\title{
FURTHER OBSERVATIONS ON THE HABITS AND PARASITES OF COMMON FLIES:
}

By G. S. GRAHAM-SMITH, M.D.

University Lecturer in Hygiene, Cambridge.

(With Plates XVIII, XIX, 23 Text-figures and 2 Charts.)

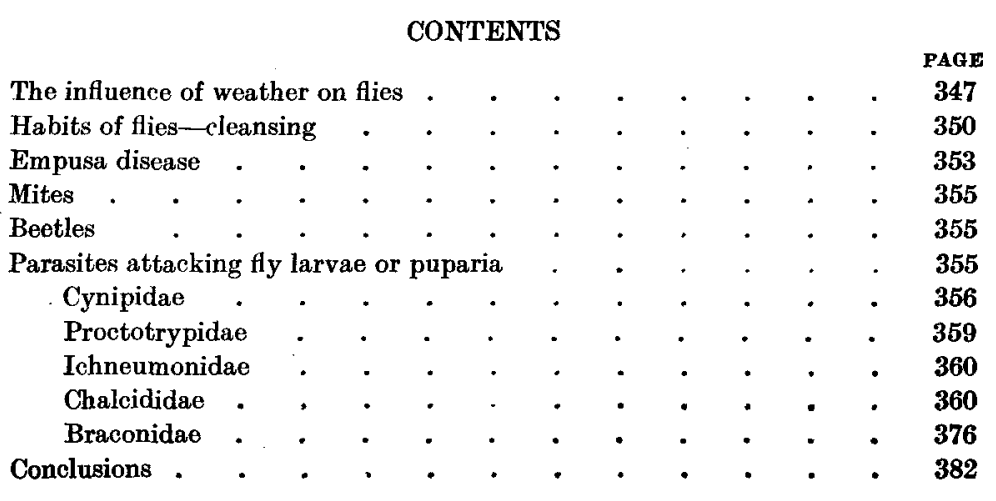

THE INFLUENCE OF WEATHER ON FLIES.

IN the year 1915 the flies caught in traps baited with various materials and placed in different situations were recorded, and charts constructed showing the effects of various meteorological conditions on flies. "These charts showed that the curve for flies caught in traps corresponded most closely to the curve for the maximum temperature recorded by a thermometer exposed to the sun" (1916, 497 and Chart 5). During the years 1916 and 1917 traps baited daily with human excrement were exposed in sunny situations, and the flies caught in them recorded. Records of the hours of bright sunshine, of the rainfall, the velocity of the wind, the maximum temperatures indicated by thermometers exposed to the sun and in. the screen, the minimum temperatures in the screen and on the grass were kept. From these observations it was possible to compare the effects of meteorological conditions on flies in three consecutive seasons.

Chart 1 shows the mean daily temperatures recorded by a thermometer exposed in the sun and the mean daily number of flies caught in a trap exposed in the open and baited with human excrement in each week during the seasons 
of 1915,1916 and $1917^{1}$. The three seasons were very different in character. In 1915 June, August and September were the finest months; in 1916 the early part of the season was dull, July and the early part of August very fine and the remainder of the season wet and unsettled; in 1917 April was very cold, May and the early part of June very fine and the remainder of the season wet and stormy.

A short summary of the weather conditions in each month is given in Table I.

\section{Table 1. Showing the weather conditions during the fly seusons of} 1915, 1916 and 1917.

1915

$\begin{array}{cc}\text { March } & \text { Very cold, last few } \\ \text { days warmer } \\ \text { April } & \text { Cold and windy, last } \\ & \text { few days fine }\end{array}$
Bright and dry, but
cold winds frequent

June

Very fine month

July

Unsettled, many cloudy days; rain fell on $\mathbf{1 6}$ days

August Mostly very tine

September Dull and windy early; later hot and oppressive; end cold

October

November Very cold
1916

Cold, windy and wet; rain fell on 23 days

Cold and windy till 21 st; later fine, warm, no rain

Up to l6th dull and damp, after 16 th very fine and warm

"Coldest June recorded at Greenwich"

To 6th fine and warm; 7 25 dull, windy, frequent showers; 26-31 very hot and fine

To 13th very fine and hot; afterwards windy, rainy, unsettled

To 20th rainy and dull; later fine

Very unsettled and rainy throughout

To 8th rain and wind; later bright but cold

\section{7}

Very cold and windy; snow fell till end of month

Frequent snow showers up to 12th; after 20th finer, but cold. "Coldest April for over half a century"

Very fine and warm. "Warmest May for over half a century"

Up to 17th very fine and warm; later cloudy and frequent showers

Very strong wind almost every day; several op pressive days with thunder

"Peculiar in the exceptional violence and duration of its gales"

Fine on the whole; 13 days of dull weather or heavy rain

Early part wet; later fine

Fine, but very windy towards end

It will be seen by reference to Chart 1 that in 1915 flies were most abundant in August and September, in 1916 in July and the early part of August and in 1917 in May and June. In each year the curve recording the number of flies caught corresponds with the curve for the maximum temperature recorded in the sun. It is evident that the appearance of flies early in the season does not necessarily indicate a great abundance in the latter part of the season.

1 These figures were obtained by adding together the maximum temperatures recorded daily and the numbers of the flies caught daily in each week and dividing the results by seven. 


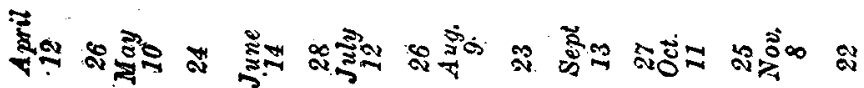

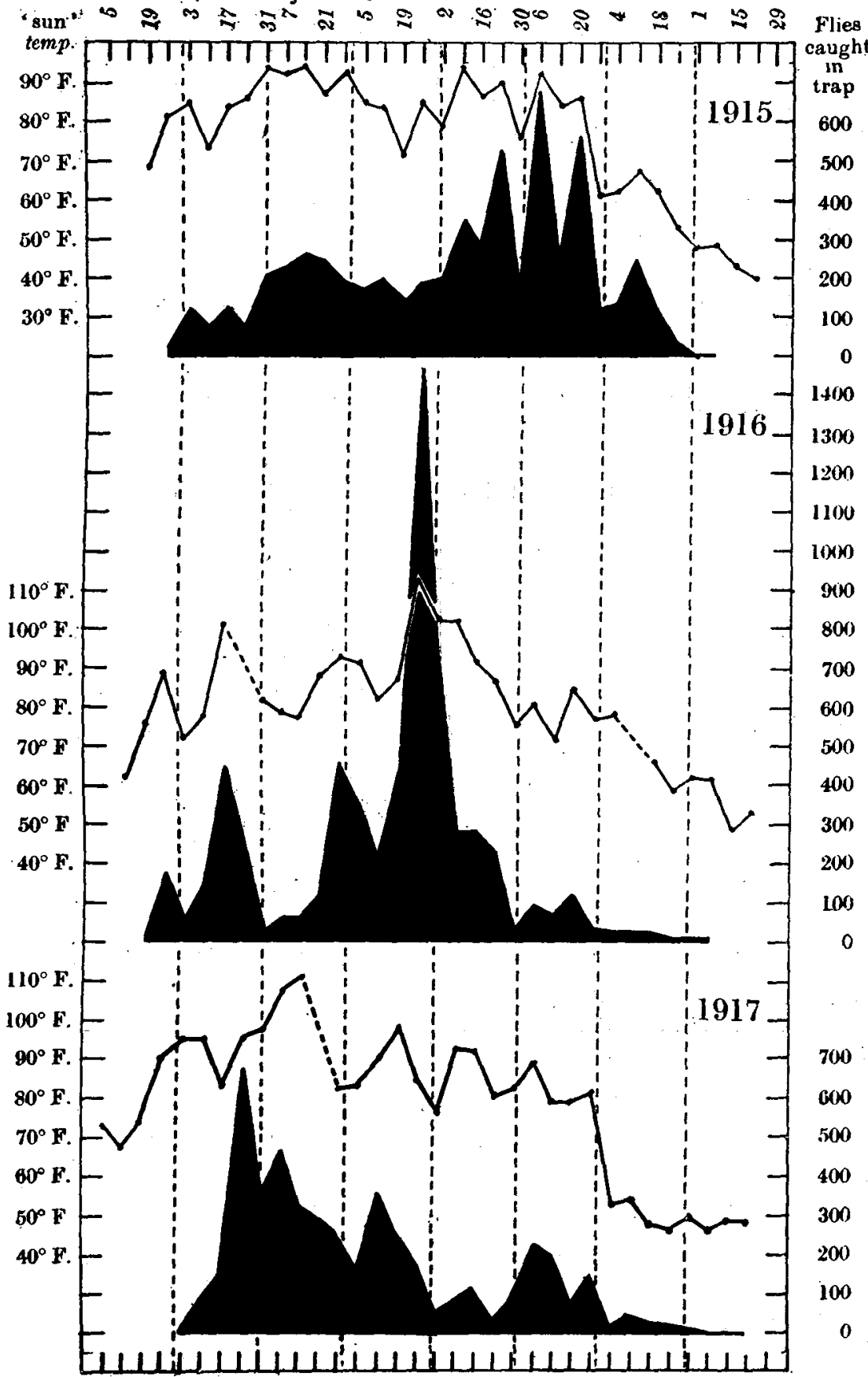

Chart 1. Weekly records of flies caught in traps baited with excrement and of "sun" temperature in the years 1915, 1916, 1917. 
On several occasions the flies caught in a trap baited with excrement were counted hourly, and the maximum temperature recorded by a thermometer exposed in the sun during each hour noted. The results obtained on two consecutive days, July 26 and 27, 1916, are shown in Chart 2. On July 26 the sun first appeared at 1.30 p.m. and the afternoon was very fine. The fly curve corresponds closely with the curve for the maximum "sun" temperature. The following day was very fine and hot throughout, and the flies were most numerous about midday. This seems to be the normal condition on very fine, sunny quiet days.

The following flies were common in 1914, uncommon in 1915 and again common in 1916: $M$. hortorum, G. maculata, $P$. albolineata, $P$. eriophthalma. $P$. greenlandica was very common in 1916.

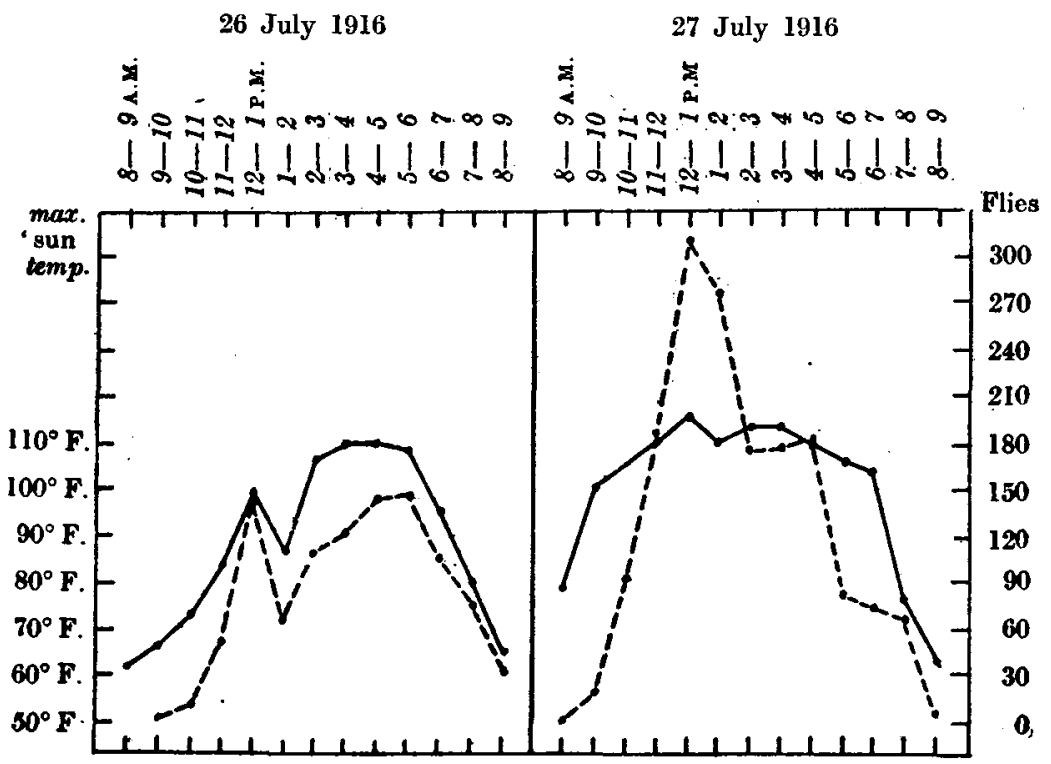

Chart 2. Number of flies caught in a trap baited with excrement (broken line) and maximum temperature recorded by a thermometer in the sun (line) during each hour on July 26 and $27,1916$.

\section{HABITS OF FLIES. ClEANSING.}

The cleansing habits of flies, especially of $S$. carnaria, were carefully studied in a large cage, $12 \times 8 \times 7 \mathrm{ft}$, out of doors-under conditions resembling as closely as possible those in which these flies live.

Throughout the day flies spend a very large proportion of their time, probably several hours daily, in cleaning themselves; not infrequently a leg or wing is being cleaned even in the act of feeding. Cleansing is almost invariably undertaken after feeding, and the procedures usually follow each other in a definite order. The wings are first treated on both surfaces, and they receive more attention than any other structure; next the posterior legs; 
after these the anterior legs; then the middle and anterior legs; next the middle and posterior legs; finally the head and proboscis. Not infrequently the wings receive further attention at intervals between the cleansing of the various pairs of legs.

The following procedures are adopted for cleaning the wings. In cleaning the upper surface of the wing the posterior leg of the same side is brought forward and bent over the proximal part of the wing as it lies horizontally along the dorsum of the fly (Pl. XVIII, figs. 7, 8), and the leg is then drawn slowly backwards along the wing towards its distal extremity. When the leg has travelled about half the length of the wing, which in consequence has been bent downwards, the opposite posterior leg is brought across under the abdomen and placed under the wing so that the tip of the wing is clasped between the two legs (PI. XVIII, fig. 9). As the legs pass backwards the tip of the wing is drawn between them, and when it escapes from their embrace springs back into its usual position (Pl. XVIII, fig. 11).

Sometimes the two posterior legs are used simultaneously for cleaning the upper surfaces of both wings (Pl. XVIII, figs. 10, 12, 21,24). Each leg is brought forwards and bent over the proximal part of the wing of the same side and then drawn very slowly backwards along the wing to its distal extremity. The under surfaces of the two wings are generally cleaned simultaneously. The wings are raised and the posterior legs are brought forward and bent in such a manner that the distal part of the leg passes under the wing with the extremity of the tarsus beyond the inner margin of the wing. The wings then seem to be pressed upwards till they are almost vertical by the elevation of the legs. While in this position they vibrate with such rapidity that it is impossible to follow the movements exactly (Pl. XVIII, fig. 23).

During these procedures the fly stands on the anterior and middle pairs of legs, the latter pair assuming the position normally occupied by the posterior pair.

When the anterior pair of legs is about to be cleaned the middle pair is brought forward in order to obtain a steady position, and the fly sits erect. Then the anterior legs are thrust forwards horizontally below the head, which seems to be held higher than usual. The cleaning movements are often slow and pauses are not infrequent while the legs are applied to each other. Sometimes the tarsi appear to be crossed and rubbed together, but more frequently the pulvillus of one leg is applied to the surface of the opposite limb, and drawn slowly along it (Pl. XVIII, figs. 1, 2, 3, 13).

When the posterior pair of legs is about to be cleaned the middle pair assumes the position usually occupied by the posterior pair, the head is depressed between the anterior legs and the abdomen elevated, so that the fly appears to be standing on its head. Then the posterior legs are thrust out backwards horizontally below the abdomen and rubbed together in the same manner as the anterior legs (Pl. XVIII, figs. 5, 6, 15, 16).

The middle legs are cleaned with the aid of the anterior or the posterior 
pairs of legs, and the procedure is usually rapid. When the anterior pair of legs is employed for this purpose the fly balances itself on the posterior pair and the opposite middle leg with its body tilted so as to slightly raise the side on which the operation is about to take place. Then the middle leg is brought forward, and rubbed between the anterior legs (Pl. XVIII, figs. 4, 17, 18). When the posterior pair is used the fly balances itself on the anterior pair and opposite middle leg with the abdomen raised and the middle leg is rubbed between the posterior legs (Pl. XVIII, fig. 19). A single anterior or posterior leg is never employed in cleaning a middle leg.

The abdomen is cleaned by passing one or other of the posterior legs over its dorsal surface from its proximal to its distal end.

The dorsal surface of the thorax is cleaned together with the upper surface of the wing, the movement of the leg commencing near the head of the fly.

When the head is about to be cleansed the middle legs are thrust forwards, and the anterior legs applied to the sides of the head in such a manner that

\section{DESCRIPTION OF PLATE XVIII.}

Photographs, natural size, of male $S$. carnaria cleaning themselves out-of-doors. Exposure $\frac{1}{30}$ sec.

Figs. 1, 2, 3. Some of the positions assumed when the anterior legs are being rubbed together. The middle pair of legs are directed forward in order to maintain a steady position.

Fig. 4. The two anterior and the left middle legs are being rubbed together, while the body is balanced on the other three legs.

Figs. 5, 6. Positions assumed when the posterior legs are being rubbed together. The middle legs are now directed backwards.

Figs. 7-12. Some of the positions assumed when the wings are being cleaned. In all cases the middle legs are directed backwards. Fig. 7. The right posterior leg resting on the proximal part of the right wing, while the left posterior leg is being elevated preparatory to being applied to the upper surface of the left wing. Fig. 8. The left posterior leg passing down the upper surface of the left wing; the right posterior tarsus is under the tip of the left wing. Fig. 9. The distal part of the right wing clasped between the two posterior legs as they are drawn backwards. The wing has been so bent that upper surface is directed outwards. Fig. 10 . The posterior legs passing over the upper surfaces of the wings. Fig. 11. Left wing about to escape from the embrace of the posterior legs. Fig. 12. Wings bent and applied to the sides of the abdomen by the pressure of the posterior legs.

Fig. 13. The anterior legs being rubbed together. Middle legs directed forwards. Side view.

Fig. 14. The proboscis being cleaned with the aid of the anterior legs. Middle legs directed forwards. Side view.

Figs. 15 and 16. The posterior legs being rubbed together. Middle legs directed backwards. side view.

Figs. 17 and 18. Anterior pair and right middle leg being rubbed together. Side view.

Fig. 19. Posterior pair and right middle leg being rubbed together.

Fig. 20. Head being cleaned between the anterior legs.

Fig. 21. Right wing elevated by right posterior leg beneath it; left wing depressed by left posterior leg passing over it.

Fig. 22. Both wings depressed by the posterior legs passing over them.

Fig. 23. Both wings elevated by the posterior legs beneath them.

Fig. 24. Posterior legs raised before application to the wings.

Figs. 13-24. The flies are resting on the edge of a piece of plate glass. 
PARASITOLOGY, VOL. XI. NOS. 3 AND 4

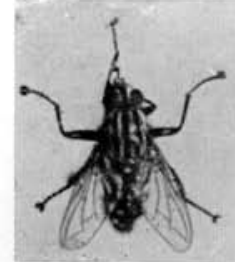

1

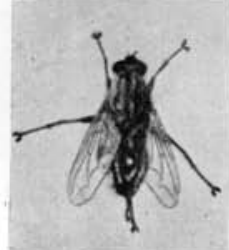

5

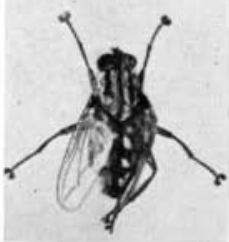

9

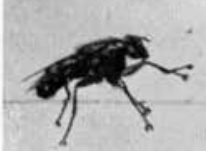

13

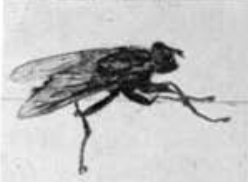

17

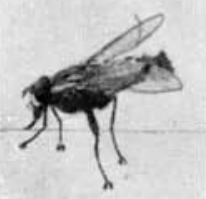

21

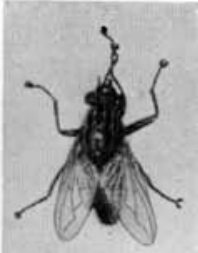

2

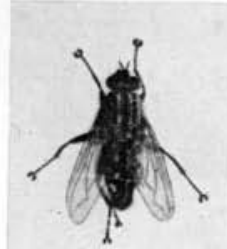

6

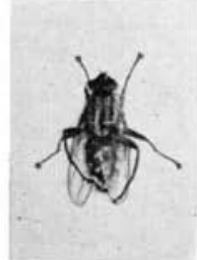

10

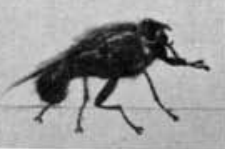

14

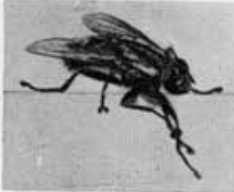

18

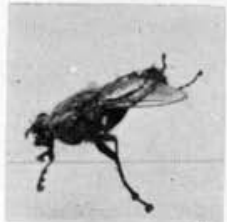

22

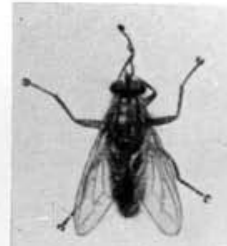

3

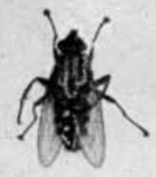

7

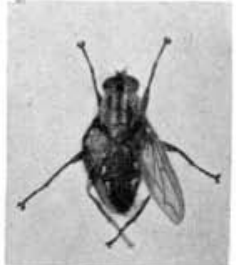

11

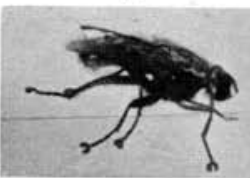

15

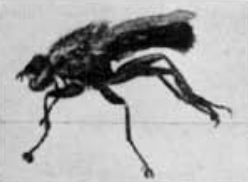

19

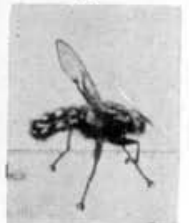

23

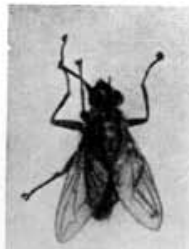

4

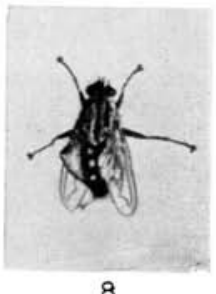

8

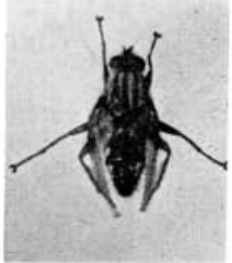

12

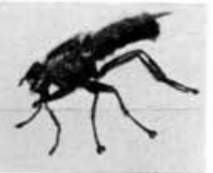

16

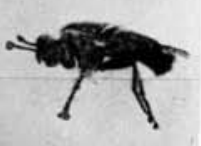

20

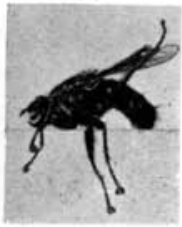

24 
the head is bent downwards bringing its posterior surface into view. The legs are then moved rapidly upwards and downwards causing the head to jerk from side to side. So rapid are the movements that the head appears to be rotating (Pl. XVIII, fig. 20).

The proboscis is cleaned with the anterior pair of legs, and the movements may be rapid or very slow. Both legs are used simultaneously, and the pulvilli, applied on each side of the extended proboscis, are passed along it from its proximal to its distal extremity. During this procedure the fly sits erect (Pl. XVIII, fig. 14).

The males of S. carnaria were chosen as subjects for these observations, because they are large, not readily disturbed, are somewhat sluggish in their motions, and have very large pulvilli, which are easily observed. Similar procedures for cleaning themselves are adopted by most of the commoner species of flies, and also by the hymenoptera parasitic on them.

During the seasons of 1916 and 1917 the habits of the two closely allied species, C. erythrocephala and C. vomitoria, were carefully noted. C. erythrocephala was caught in traps almost daily, but $C$. vomitoria only occurred commonly in the traps on fine days with little wind. $C$. vomitoria and $H$. dentipes seem to dislike great heat and are seldom found on windy days, especially if very hot. On the other hand Lucilia and O. leucostoma are seldom caught in traps on sunless days, but are very common and active on hot, sunny days.

It was noticed in both years that newly emerged flies are greatly attracted to excrement, and that in the early part of the season decomposing animal matter attracts few flies, presumably because the majority are not ready to oviposit.

In October 1917 some much decomposed animal remains containing many small larvae were buried to a depth of 18 inches. This material was exhumed on February 13, 1918, when the larvae were found to be alive and nearly full fed.

It may be of interest to record the fact that when digging in the face of a sand pit on April 20, 1917, two male Onesia cognata were found at a depth of 18 inches from the surface, and some inches from the face of the pit. A distance of 9 feet separated the two flies, which were very sluggish, but soon became active on exposure to the sun.

\section{EMPUSA DISEASE.}

The writer has shown previously $(1916$, p. 507) that records relating to the infection of flies, other than house-flies, with empusa are rare. He described the infection in four specimens of $\boldsymbol{H}$. dentipes, two of $\boldsymbol{F}$. canicularis and in C. erythrocephala.

In the year 1916 very careful observations were made and 34 specimens of $H$. dentipes infected with the disease were found outside between July 5 and September 11. In that year it was first seen in M. domestica on September 27. 
In 1917 and 1918 infected specimens of $H$. dentipes were found in July and the disease was first noticed in $M$. domestica on September 13, 1917, and on July 25,1918 . In $H$. dentipes the symptoms develop with very great rapidity. For example an apparently normal specimen caught in the morning was dead and showed well marked rings round the abdomen by 6.30 in the evening. After a certain period a halo of spores is thrown out round the body. As previously suggested (1916, p. 507) the infection may spread from such flies as $H$. dentipes, which develop the disease in the middle of summer, to M. domestica or its larvae.

In 1916 infected specimens of Lucilia were found outside on July 7 and August 22 (Pl. XIX, fig. 4) and in 1917 a specimen on July 2.

In 1917 six infected specimens of $F$. canicularis were found indoors on October 1 and 7 and November 9 and 14 .

On August 13, 1917, an infected specimen of an A. radicum was found on a window.

On August 3, 1916, an epidemic commenced amongst 28 specimens of S. carnaria kept in a cage out of doors. Thirteen of the flies died with very well marked signs of the disease on August 3, nine on August 4, and two on each of the three succeeding days.

On August 7 seven wild specimens were caught and placed in the cage. All died of the disease, one on August 9, one on August 10, and five on August 14. Spores were thrown off in the form of a halo round the dead flies (P1. XIX, fig. 5). Subsequently wild flies of several species were put into this cage, but did not develop the disease. S. carnaria therefore seems to be extremely susceptible when exposed to the disease, but the infection of this species has never been recorded previously.

\section{DESCRIPTION OF PLATE XIX.}

Fig. 1. Blow fly (C. erythrocephala) with a large drop of fluid ("vomit") which had been regurgitated adhering to its proboscis. The drop was subsequently withdrawn. Nat. size.

Fig. 2 . M. stabulans, sitting on the top of a wall, with a drop of dark coloured, regurgitated fluid adhering to its proboscis. Nat. size.

Fig. 3. Fly with numerous hypopial nymphs adhering to its thorax and head. $\times 5$.

Fig. 4. A specimen of $L$. caesar dead of empusa disease adhering to an artichoke leaf. Nat. size.

Fig. 5. Specimen of $S$. carnaria dead of empusa disease, surrounded by a halo of spores. Nat. size.

Fig. 6. A. manducator ovipositing in a larva of $C$. erythrocephala. Nat. size.

Fig. 7. A Figitid emerging from a puparium. $\times 5$.

Fig. 8. Cork of a test-tube in which several specimens of $M$. acasta were confined. Two grooves gnawed by the females are shown (see p. 363). Nat. size.

Fig. 9. Puparia from which $A$. cephalotes emerged (upper row), and from which Figitids emerged (lower row). Nat. size.

Fig. 10. Puparium opened longitudinally showing living nymphs of $M$. acasta (see p. 363). $\times 4$.

Figs. 11, 12. A Proctotrupid (Trichopria, sp.) male and female. $\times 8$.

Figs. 13, 14. M. acasta, male and female. $\times 10$. 
PARASITOLOGY, VOL. XI. NOS. 3 AND 4

PLATE $X I X$

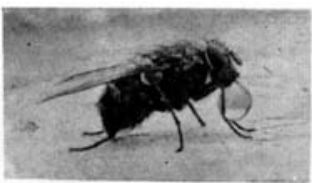

1

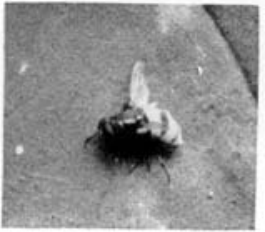

4

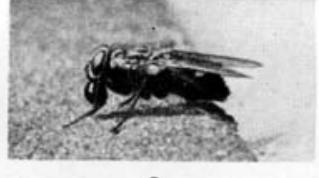

2

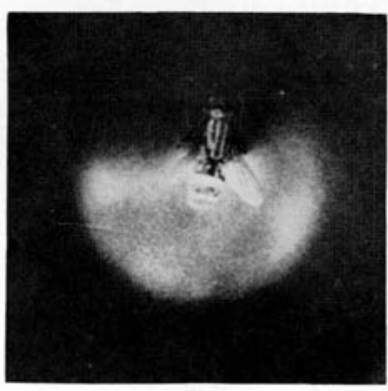

5

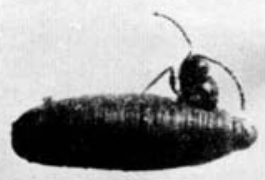

7

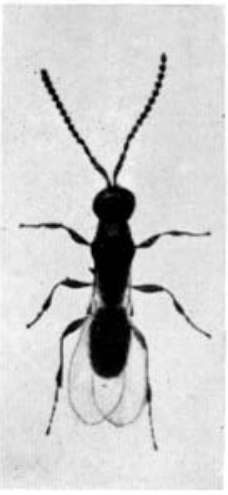

11

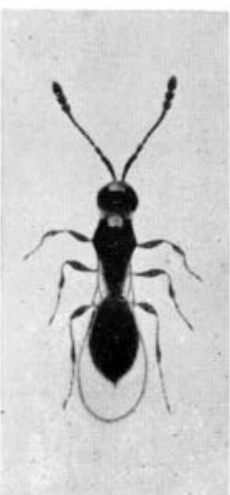

12

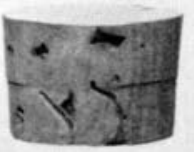

8

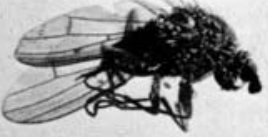

3

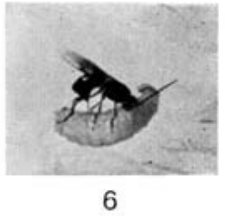

10

111

9

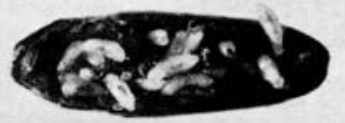

10

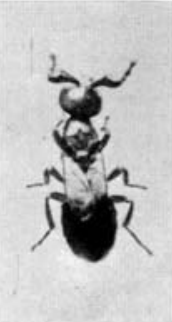

13

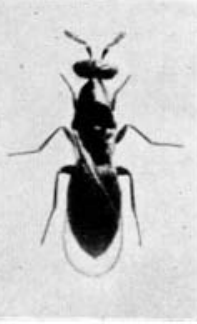

14 
In September 1916 a large number of $M$. corvina confined in another cage outside all died of the disease.

In June 1918 Keilin observed great numbers of $S$. stercoraria dead of the disease clinging to nettles in a meadow near Cambridge.

\section{MITES.}

The Gamasid mites previously described (1916, p. 511) were very common on animal remains and faecal matter containing fly larvae during 1916 and 1917, and their habits were more closely observed. They were often seen to attack and kill freshly hatched larvae. They also feed on the eggs of flies, sucking out their contents and rejecting the shrivelled integument. These mites occur in very great numbers, and must cause the destruction of great numbers of eggs and young larvae.

Red mites were seen attached to the legs and bodies of Lucilia and $H$. dentipes in July and August in both 1916 and 1917.

\section{BEETLES.}

Beetles of various species seriously interfered with several experiments, and are probably beneficial by destroying both larvae and pupae under natural conditions. In one experiment a jar containing fly puparia was left exposed in the open. On examining this jar a few days later 22 specimens of Creophilus maxillosus were discovered in it, and almost all the puparia were found to be torn open and destroyed. This beetle is a strong flier, and is readily attracted to all decomposing materials.

Two other species (Necrophorus humator, Hister cadaverrinus), very common in decomposing animal matter, seem to be destructive to larvae and pupae.

Even buried puparia may be attacked, for in another experiment a large number of puparia buried at a depth of 2 inches were found torn in pieces. One of the beetles (Pterostichus madidus) attacking these puparia was closely observed for some time. It carried off a puparium holding it in its mandibles by one end. The puparium was taken from it, and placed on the ground a short distance away. The beetle immediately searched for it, found it, and took it up and finally disappeared with it into a crevice in the ground.

Dr G. W. Nicholson very kindly identified several species of beetles submitted to him.

\section{PARASITES ATTACKING FLY LARVAE OR PUPARIA.}

Since the autumn of $1915 \mathrm{fly}$ larvae and puparia collected at various times have been kept under observation in separate receptacles, with notes recording their origin and date of collection. From these naturally infected puparia members of the five most important families of the Hymenoptera parasitica or Terebrantia, the Cynipidae, Proctotrypidae, Chalcididae, Ichneumonidae and Braconidae, have been obtained. 
These parasites undoubtedly play an important part in restricting the numbers of adult flies which emerge, but hitherto the species parasitic on diptera have been greatly neglected. From their economic importance, the diversity of their habits, and the peculiarities of their structure, these parasites deserve more attention than they have received, and it is with the hope of calling attention to them that the following observations have been recorded. For the same reason a sketch of each species, showing the appearance of the insect, has been inserted. Though such drawings are of no value for determining species, they indicate roughly the characters of insects belonging to different families and illustrate the remarkable diversities of their forms.

Many of the genera embrace scores of species most difficult to identify, and many species are as yet undescribed.

Dr R. C. L. Perkins most kindly examined the examples of the Cynipids and Proctotrupids, Mr J. Waterston several of the Chalcids, Mr C. Morley the Ichneumons and Mr G. T. Lyle the Braconids. Prof. Masi of Genoa, in the absence of Mr Waterston, very kindly identified Necremnus leucarthros.

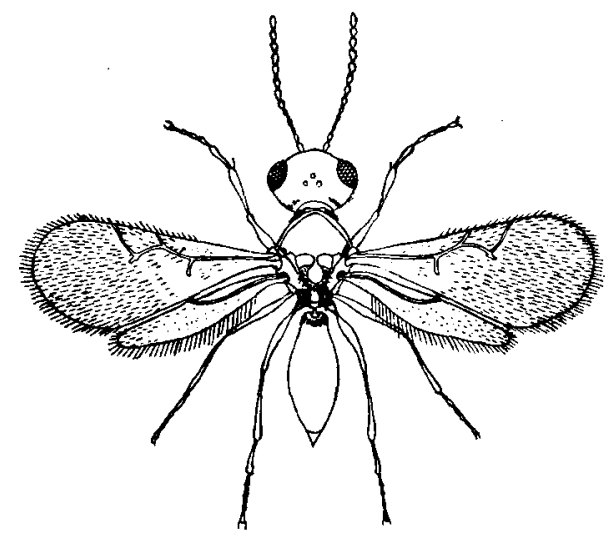

Fig. 1. Diranchis sp. ㅇ. $\times 20$.

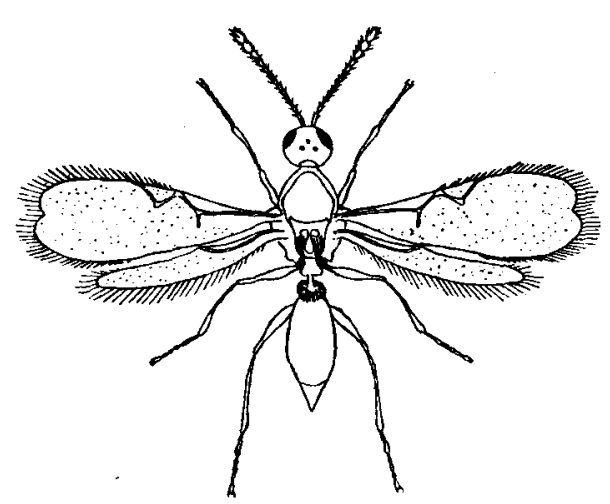

Fig. 2. Kleidotoma sp. ㅇ. $\times 20$.

\section{CYNIPIDAE.}

Of this family 4 specimens, $2 \delta$ and 2 \%, of a species of the genus Diranchis (Först) emerged in June 1916 from puparia collected in the autumn of 1915.

Five specimens, $3 \stackrel{A}{a}$ and 2 , of a species belonging to the genus Kleidotoma (Westwood) emerged in June 1917 from puparia collected in faecal material in the autumn of 1916.

A species of the genus Figites emerged in May and June 1916 and 1917 from puparia collected in the preceding years and kept under circumstances which precluded the possibility of spring infection. It was noticed that they appeared from puparia kept outside in a warm situation nearly a month earlier than from puparia kept in the shade. Altogether 73, $28{ }^{*}$ and $45 \%$, emerged during these two years. The percentage of infection was very small. For example from one batch of 4280 puparia from larvae feeding on exposed meat only 
$25(0.6$ per cent.) of these parasites emerged, though throughout the season from June to October the adult parasites were constantly present amongst the larvae, presumably with the intention of ovipositing.

From the exposed carcase of a small animal fluid soon exudes, and in places the surface of the carcase becomes semi-liquid. In these situations very small larvae are numerous. Folds in the skin of the carcase, or crevices in the meat, contain similar material. The Figitids are usually found walking over the semi-liquid material where they may be seen making frequent, quick, stabbing movements with their ovipositors, which are very long and fine. These parasites oviposit in very small larvae only. Sometimes the larvae selected are near the surface and visible, but often they are buried in semifluid material and are probably quite invisible to the parasite. In such cases the larvae appear to be discovered with the aid of the ovipositor. The process

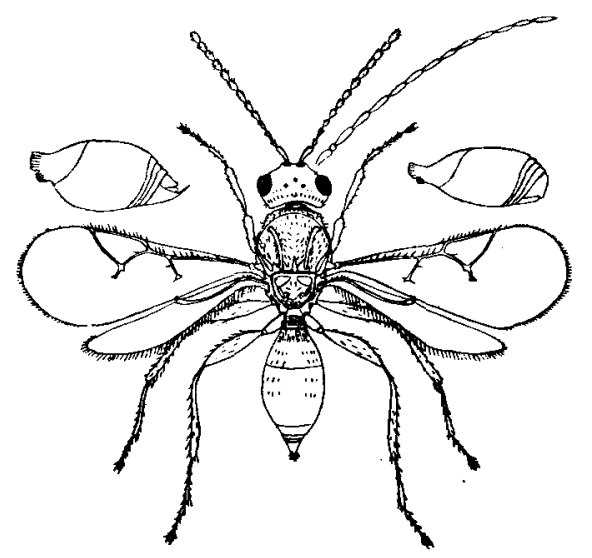

Fig. 3. Figites sp. . $. \times 20 . \hat{o}$ antenna. $\hat{\sigma}+q$ abdomen, side view.

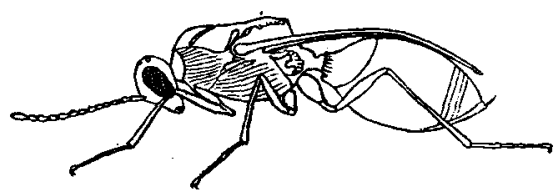

Fig. 4. Figites sp. ㅇ. Side view showing position of wings when walking in wet material.

of oviposition occupies 1 to 2 minutes. When in search of larvae amid wet and slimy surroundings or when penetrating into crevices in putrid meat, the Figitids walk in a peculiar manner with the wings folded over the back and the terminal portions bend downwards and closely applied to the dorsal surface of the abdomen. The wings look as if soiled, but this is not the case for on being alarmed they fly off easily, and the position seems to be adopted for the purpose of protecting the wings.

Neither under experimental nor natural conditions were the Figitids seen to attack any but very small larvae. They took no notice of eggs, large larvae or puparia. 
Only a single parasite emerged from an infected puparium, and in all the cases observed the puparium was a small one. The opening through which the parasite emerges is irregular (Pl. XIX, figs. 7, 9).

Experimentally this parasite was seen to oviposit over a period of 4 or

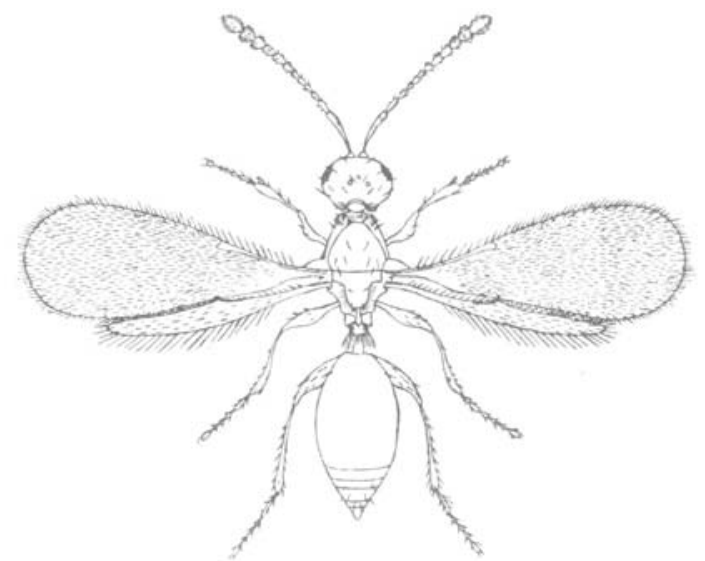

Fig. 5. Trichopria sp. 우. $\times 20$.

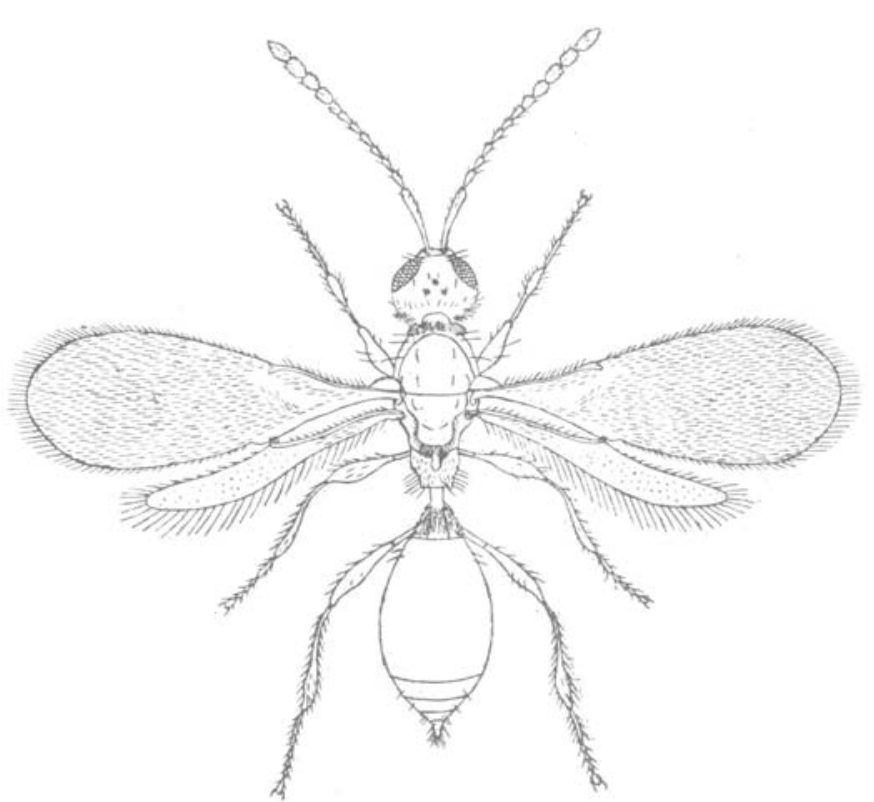

Fig. 6. Trichopria sp. ㅇ․ $\times 20$.

5 days. From ova deposited in September 1916 in very small larvae confined in tubes, imagines appeared in June and July 1917.

It will be noticed that all the three species observed passed the winter in fly puparia. 
PROCTOTRYPIDAE.

Of this order 4 species were obtained. The commonest was a species of the genus Trichopria of which 61 specimens, $15 \%$ and $46 \%$, emerged in June 1917 from puparia collected in the autumn of 1916 from larvae feeding on faecal material. Other specimens emerged in September 1917 from puparia

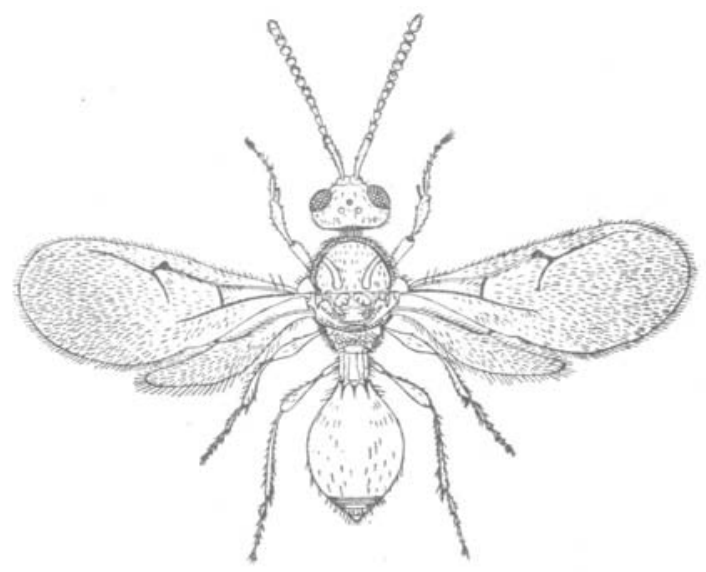

Fig. 7. Aneurrhynchus sp. $\times 20$.

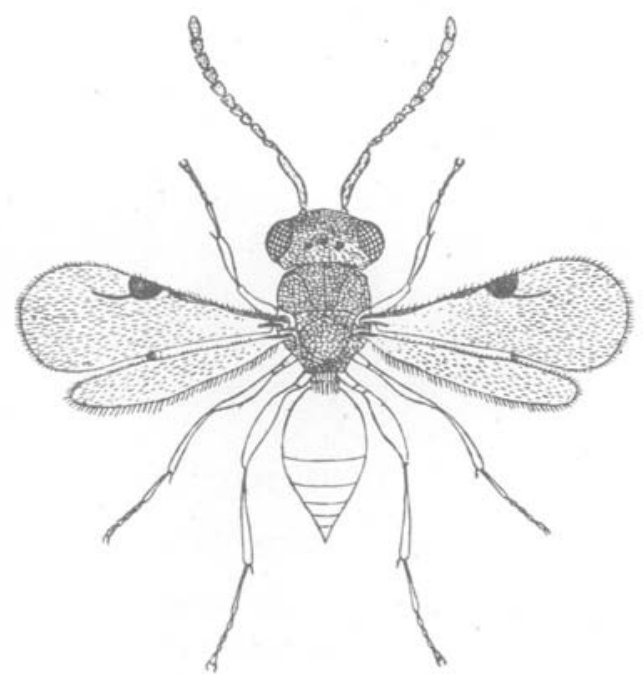

Fig. 8. Conostigmus sp. $\times 20$.

collected earlier in the same season. Eleven specimens, $4 \delta$ and $7 q$, of another species of Trichopria (? elongata, Thoms.) emerged in September 1917 from puparia found in faecal material in June. Very shortly after emerging, many had mites attached to them.

Three specimens of a species of the genus Aneurrhynchus appeared in July 1916 from puparia collected in the autumn of 1915 from larvae feeding on 
meat, and one specimen of a species of Conostigmus or Lygocerus in May 1916 from a puparium collected in the autumn of 1915.

These parasites being very small easily escape observation, and it is probable that many species infest the diptera.

\section{ICHNEUMONIDAE.}

Only 4 Ichneumons were obtained, all from puparia of $C$. erythrocephala, 1 o Phygadenon speculator, Thoms. in July 1916 from a puparium collected earlier in the season, and $1 \delta$ and 29 of Atractodes bicolor Gravenh. in June and October 1916 from puparia collected in the summer of 1915 (shade tin).

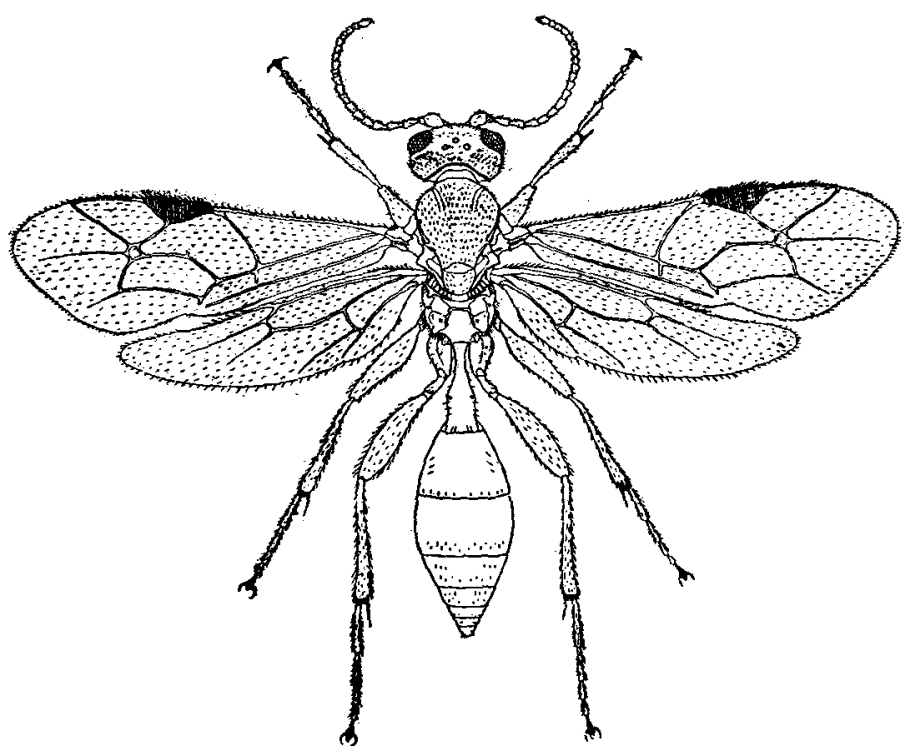

Fig. 9. Atractodes bicolor $9 . \times 12$.

CHALCIDIDAE.

Melittobia acasta Wlk.

Great numbers of fly puparia kept under observation during the winter of 1914-15 were found to be naturally infected by $M$. acasta. "Every puparium attacked by the chalcid was found to be lined by the thick membrane characteristic of a puparium containing a braconid larva." These observations have been quoted in detail (1916, pp. 532-535). At the time of examination (in the winter of 1915-16) a number of intact puparia were discovered from which neither flies, braconids nor chalcids had emerged. Some were dissected and found to contain living chalcid larvae and remains of braconid larvae, but 370 were kept for further observation and placed in jars in a warm room $\mathrm{E}$ and a cooler room $\mathrm{B}$. One jar in room $\mathrm{E}$ contained 16 puparia, each in a 
separate tube. On April 252 o Dibrachys cavus emerged from 1 puparium. Between May 6 and $196 \delta$ and 96 o $M$. acasta developed in 12 puparia. Another contained living chalcid larvae and two others dead fly larvae (for details see 1916 , p. 543).

On June 10, 1916, 13 puparia were placed in a jar in this room and $M$. acasta commenced to emerge 9 days later. In 11 of these puparia 18 and 201 우 developed.

From the 341 puparia kept in the cooler room B $M$. acasta commenced to emerge at the end of July. In 117 puparia 114 ot and 1613 \& $M$. acasta developed and $D$. cavus in 9 . Six puparia were dissected at various times, and no parasites emerged from the remaining puparia, which were kept under observation for a year and dissected in April 1917. In 101 of these dead specimens of $M$. acasta were found, in 25 living or dead larvae of $A$. manducator and in 83 dead fly larvae or pupae.

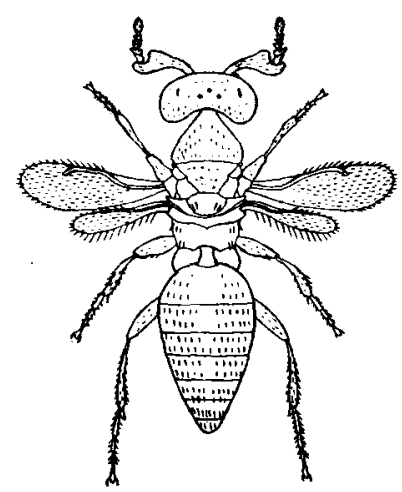

Fig. 10. Melittobia acasta $ð . ~ \times 20$.

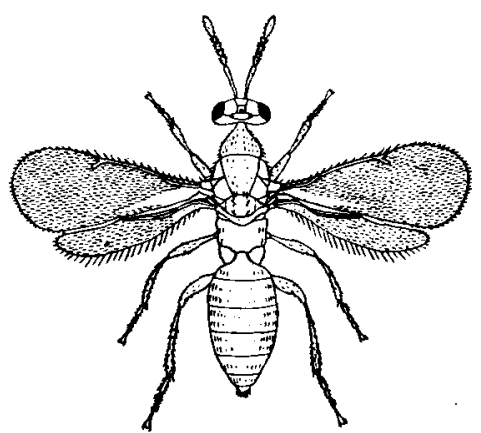

Fig. 11. Melittobia acasta 우. $\times 20$.

These observations show that the emergence of $M$. acasta is greatly hastened by warmth, and that this parasite, when it attacks puparia already parasited by $A$. manducator, may emerge from fly puparia nearly two years old.

It is of interest to note that of the 370 puparia remaining intact after one year's observation 242 or 65 per cent. yielded living or dead adults or larvae of $M$. acasta. Living chalcids, 138 of and 1925 o, developed in 140 of the puparia, giving a mean of $1 \delta$ and 13 in each puparium. The mean number emerging from each puparium is small, and this is due perhaps to the fact that all the puparia were previously infected by $A$. manducator.

Similar observations were made with very large numbers of fly puparia kept under identical conditions during the winters 1915-16 and 1916-17. In the former year only one puparium infected with $M$. acasta ( 1 and 7 o) was observed, and in the latter none. In both years, however, severe infections with other chalcids occurred. 
Experiments with M. acasta.

From $M$. acasta which emerged in 1916 several generations were reared on healthy puparia of several species of flies, and some observations made on their habits under these conditions. In most of these experiments the chalcids and the puparia were kept in small corked glass tubes, the contents of which could be examined easily under a binocular dissecting microscope.

\section{Oviposition.}

When a $o$ is placed in a tube with a fly puparium she soon begins to walk over it, stopping at frequent intervals and apparently examining the surface. Eventually a place is chosen and the ovipositor applied. During the process of inserting the ovipositor the position of the legs is not changed, but the whole body is raised and lowered rhythmically by movements of the tarsi. At each movement of the body the ovipositor seems to be rotated through a quarter of a circle. Eventually the ovipositor is completely buried. The whole process frequently occupied 2 hours.

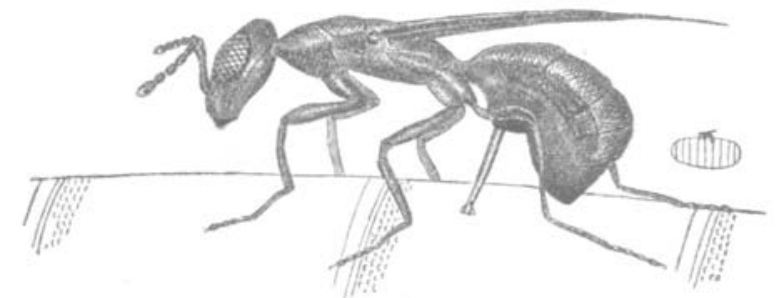

Fig. 12. Melittobia acasta ovipositing in a puparium.

One $q$ was seen ovipositing over a period of 48 days and another over a period of 37 days. Fly larvae, whether large or small, did not attract the chalcids, and no attempt was ever made to oviposit in them.

On carefully dissecting a healthy fly puparium a few days after oviposition the eggs of the chalcid, which measure $0.275 \times .0875 \mathrm{~mm}$. and are sticky, are found in groups up to the number of 12, though single scattered eggs are also seen, on the surface of the nymph. The larvae, which emerge from these eggs, remain on the surface of the fly nymph, but become partly imbedded in shallow grooves. Where a puparium already infected by a braconid was attacked only small numbers of chalcid eggs were found lying on the surface of the braconid larva.

\section{The development of $\mathrm{M}$. acasta larvae.}

The events, which occur during the later stages of the larval life of $M$. acasta, may be followed by opening the infected fly puparia and keeping them in glass topped boxes in the dark. Such opened puparia with $M$. acasta larvae within them have been illustrated previously (Graham-Smith, vIII. 1916, Pl. 
XXX, figs. 13, 15 and 16). Three puparia were opened in December 1915 (Graham-Smith, 1916, virr. p. 543) and kept together in a glass box in a warm room. The $M$. acasta larvae, which were white and glistening, remained almost motionless for five months. On May 22 excrement was deposited, and many of the larvae had changed into white glistening nymphs by May 30 . The of nymphs became dark brown in colour and the $q$ nymphs black. This change in colour is gradual, and many of the + nymphs may be white when others have become black. The first $\delta$ emerged on June 13, and two others in another puparium on June 26. The latter two os fought and one of them killed the other. At this date the $q$ nymphs were still white. Another $\hat{\alpha}$ emerged on July 9 and was killed by the one which had emerged previously. The surviving ofs each kept guard over the $q$ nymphs in his own opened puparium. By July 2 two of the + nymphs had become black. The first $q$ emerged on July 17, and shortly afterwards mated with the ${ }^{*}$, which had previously emerged in her puparium. Two os emerged on July 27 and several female nymphs had become black by the time. On July 31 several adult is emerged, but many of the female nymphs were still white.

It is evident from the observations recorded in the following paragraphs that in these opened puparia the events occurred in the same order as they do under natural conditions in intact puparia. The ots develop into imagines many days before the $q s$, and fights between them are of frequent occurrence in which the weaker are mutilated, or killed. The survivor remains in the puparium and mates with the os soon after they emerge.

\section{The emergence of M. acasta from fly puparia.}

The of of M. acasta emerge from an intact fly puparium through a small round hole, which one of them gnaws. The hole is usually situated near one end of the puparium, but is occasionally near the centre. Very rarely two such holes are produced in a puparium. (Graham-Smith, 1916, Pl. XXX, fig. 10.) The hole is only just large enough to allow a 9 to pass out, but is not large enough to admit of the passage of a $\delta^{*}$. Occasionally a $q$ has been seen to re-enter a puparium through such an opening, but usually after they have emerged the os fly away. On one occasion, when the opening was blocked by the body of a $q$ which had died while attempting to emerge, another $q$ which wished to re-enter enlarged the opening from the outside. Since the os are usually too large to emerge through the holes made by the $q$ it is very rare to find one outside a puparium, and they seem to spend their lives within the puparia. This accounts for the large number of bodies of males found within puparia in previous observations (Graham-Smith, 1916, p. 532). The os are fertilised before they emerge from the puparia.

Judging from the behaviour of the parasites when kept in glass tubes only one $q$ is engaged at one time in the work of boring through the puparium, however many there may be within the puparium ready to emerge. This would account for the fact that multiple openings in puparia are very rare 
and that numbers of females are often seen emerging one after the other from a puparium through a single opening.

If several is are confined in a corked tube they often endeavour to escape by excavating a tunnel through the cork. In one instance a tunnel $3 \mathrm{~mm}$. long and about $0.5 \mathrm{~mm}$. in diameter (Pl. XIX, fig. 8) was excavated in the part of the cork in contact with the glass, and all the os, 40 in number, escaped through it. In this case, as in many others, the process was carefully watched. Only one $q$ worked at a time, and the others remained quietly cleaning themselves in various parts of the tube. When the worker retired another took her place, and no attempt was made to start fresh channels.

Sometimes though the parasites become adult they fail to emerge from the puparium and die. The cause of this phenomenon has not been ascertained.

Habits of M. acasta.

Males. As mentioned previously the males usually reach the adult condition several days or even weeks before the females in the same puparium. The males vary greatly in size and colour. The largest reaching a length of $2.25 \mathrm{~mm}$. and the smaller specimens only $1.25 \mathrm{~mm}$. They are larger and more stoutly built than the females, but they appear to be blind and owing to their ill-developed wings are incapable of flight. Their colour varies from light yellow to brown.

The males which emerge in opened puparia (see p. 363) remain there though free to get away, if they desire to do so. They sometimes move slowly about amongst the female nymphs, frequently touching them with their antennae and apparently examining them closely, but spend most of their time in cleaning their antennae and legs. If two males emerge in the same puparium they soon meet and fight.

The habits of the males are more easily studied in glass tubes, especially when confined with females. A single male was frequently seen to mate with many females. It may be mentioned that when a male has been present all the females which leave a puparium seem to be fertilised. Though all the movements of the males are slow, and they are seldom in motion for more than a few seconds, their attitude is alert. Especially when in the neighbourhood of other males they walk with the antennae lifted, widely separated, and waving in a peculiar menacing manner. When two males approach one another a fight almost invariably occurs, and a living male has been seen to attack the shrivelled body of a dead male.

Several of these fights were carefully observed. One between two large specimens of almost equal size lasted nearly an hour. Much of the time was occupied in manœuvring to obtain favourable positions. Eventually one specimen was able to get on to the back of the other, and, securing a firm hold with his legs, buried his mandibles in the dorsal part of his adversary's head, and continued to bite for five minutes. During this time the other ceased to 
struggle. As soon however as the hold was relaxed the wounded specimen made attempts to get away. In this he was not successful for the first male again succeeded in getting on to his back, and after biting off a wing, buried his mandibles in his opponent's back and bit savagely several times. After this the injured male made great efforts to get away and succeeded. Although he had been badly injured and died within a few hours, he seemed from his actions to be prepared to attack his adversary, if opportunity offered. The victor appeared to be much troubled by the fragments which found their way between his mouth parts, for even during the fight he often tried to remove them by passing his legs between his mandibles and subsequently rubbing them together.

In many instances when several males were placed in a tube all except one were found dead and mutilated within a few hours. On one occasion when a puparium was opened two males were found within, one, though still able to stand, without his head. On another occasion a puparium on being opened contained 13 o , 13 female nymphs, and one large, active living male. The mutilated remains of seven other males were also found. Only very rarely was more than one living male found in a puparium.

Females. The females have large eyes and well developed wings, and can fly for a considerable distance. Liberated specimens were often seen to fly for some feet. Usually, however, they only fly for very short distances, one or more inches, in a jerky manner. Their movements are very rapid, unlike the slow movements of the males, and they are very frequently in motion. Much time is spent in cleaning their legs, wings, antennae and bodies, in the same manner and as thoroughly as flies. As previously stated they are apt to burrow through the corks of the tubes in which they are confined, whereas the males never attempt to do so. The females are ready to mate with the males very soon after emerging.

Females, whether fertilised or unfertilised, confined with fly puparia in glass tubes live a long time. The longest periods noted were 95 and 79 days. The mean duration of life of 40 unfertilised females was 36 days and of 18 fertilised females 33 days. These females seem to derive their nourishment from fluid exuding from puparia, which have been punctured by the ovipositor of the parasite.

\section{Experiments with fertilised females.}

A number of experiments were carried out with females either derived from puparia containing males or kept in tubes with males. It was presumed that they had been fertilised. In most experiments a single such female was confined in a tube with one or more fly puparia. In some instances the puparia were removed after a few days to other tubes and the female given fresh puparia. In all cases the parasites which emerged were counted, and the puparium subsequently dissected to ascertain the number of males and living female nymphs still present in it. Even when no parasites emerged the puparia 
were dissected. The tubes were examined daily and the duration of the life of the female noted.

The results are given in Table II. It will be noticed that female No. 3 was observed to oviposit over a period of 43 days, and produced 70 and 325 \% and 20 nymphs and No. 16 oviposited over a period of 35 days and produced $4 \delta$ and 159 o and 5 nymphs. On the other hand one puparium given to female No. 20 contained only 8 , a puparium given to No. $151 \sigma^{*}$ only, and a puparium given to No. 161 o and 2 \%.

The first parasites emerged on the twenty-third and the last on the fiftieth day after the commencement of the experiment. In one case (No. 2) eggs were deposited only in the first puparium which was given, in another (No. 15) only in the second out of three lots of puparia given, in another (No. 16) only in the second and third out of four lots. In some of the experiments the parasites emerged from some of the puparia and were found dead in others. It was common to find dead fly remains, without any trace of the parasites, in dissected puparia possibly indicating that the flies had been killed in some manner by the puncturing of the puparia.

In the course of these experiments 36 o were confined in tubes with 174 fly puparia and in 35 (20 per cent.) of these puparia the parasites developed, and in 2 ( 1 per cent.) $M$. acasta larvae on dead $A$. manducator larvae were found. From 52 (29.9 per cent.) of the puparia flies emerged, and from 3 ( 2 per cent.) A. manducator. In 76 (43.6 per cent.) dead fly remains and in 6 (3 per cent.) living $A$. manducator larvae were found.

The 33 infected puparia contained $46 \curvearrowright, 1335$ o and 189 female nymphs, a mean of $1 \delta, 40 q$ and 6 nymphs in each puparium.

\section{Experiments with virgin females.}

In order to secure virgin females for these experiments infected puparia were opened and female $M$. acasta nymphs removed and placed in tubes till they emerged. At varying times after emergence fly puparia were added. Forty-one experiments were carried out, and in each only one female was employed. To these females 225 fly puparia were given. All those puparia from which flies did not emerge were dissected subsequently and the contents noted. In eight instances after the removal of the first batch of puparia a second batch together with a male $M$. acasta was placed in the tube.

From the 225 puparia given to the virgin females 53 (23.5 per cent.) flies, 6 (2 per cent.) A. manducator and one Ichneumon emerged. $142(63 \cdot 1$ per cent.) contained dead fly remains, 16 (7 per cent.) dead $A$. manducator and 3 ( 1 per cent.) living and 4 ( 1 per cent.) dead $A$. manducator larvae.

In 15 ( 7 per cent.) of the puparia one or more male $M$. acasta were found. In eleven instances with dead fly remains, in three with dead $A$. manducator and in one with a dead $A$. manducator larva. Two puparia contained $4 \delta$, five $2 \sigma$, eight $1 \sigma$. A living $M$. acasta larva was also found on one occasion with dead fly remains. Females were never encountered, and in no case had the 
Table II. Showing results of experiments with fertilised females of M. acasta.

\begin{tabular}{|c|c|c|c|c|}
\hline $\begin{array}{l}\text { o. of } \\
\text { peri- }\end{array}$ & $\begin{array}{l}\text { No. of } \\
\text { females }\end{array}$ & $\begin{array}{l}\text { No. of } \\
\text { puparia }\end{array}$ & $\begin{array}{l}\text { Age of } \\
\text { female } \\
\text { in davo }\end{array}$ & Results \\
\hline & & & in days & Infected, puparia \\
\hline 1 & 1 & 1 & 2 & (1) $2 \hat{\sigma}+56 q$ on 39 th day \\
\hline 2 & 1 & $\begin{array}{l}1 \\
1 \\
1\end{array}$ & $\begin{array}{r}2 \\
20 \\
31\end{array}$ & (1) $1 \jmath+12 q+47$ larvae on 35th day \\
\hline 3 & 1 & $\begin{array}{l}1 \\
1 \\
1 \\
1 \\
1\end{array}$ & $\begin{array}{l}5 \\
21 \\
31 \\
37 \\
48\end{array}$ & $\begin{array}{l}\text { (1) } 2 \sigma^{*}+78 q+4 \text { larvae on } 36 \text { th day } \\
\text { (1) } 1 \sigma^{\lambda}+118 q \text { on } 28 \text { th day } \\
\text { (1) } 4 \sigma^{*}+129 q+16 \text { nymphs }\end{array}$ \\
\hline 4 & $\mathbf{1}$ & 2 & 5 & $\begin{array}{l}\text { (1) } 1 d^{t}+41 \text { on } 36 \text { th day } \\
\text { (2) } 1 d^{t}+17 \text { on } 43 \mathrm{rd} \text { day }\end{array}$ \\
\hline 5 & 1 & 2 & 2 & - \\
\hline 6 & 1 & 2 & 6 & - \\
\hline 7 & 1 & 2 & 5 & $(1,2)$ many $z+q$ \\
\hline 8 & 1 & 5 & 5 & $\begin{array}{c}(1-4) 4 \delta^{t}+202 \%+39 \text { nymphs on } 37 \text { th } \\
\text { to } 43 \text { rd days }\end{array}$ \\
\hline 9 & 1 & 6 & 5 & $\begin{array}{l}\text { (1-6) } 8 \hat{0}+190 \text { o }+9 \text { nymphs on } 37 \text { th } \\
\text { to } 50 \text { th days }\end{array}$ \\
\hline 10 & 1 & 6 & 5 & - \\
\hline 11 & 1 & 6 & 5 & 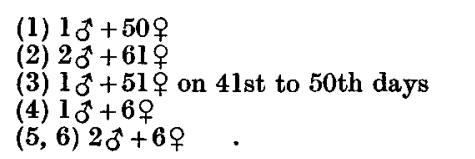 \\
\hline 12 & 1 & 6 & 5 & - \\
\hline 13 & 1 & 6 & 5 & - \\
\hline 14 & 1 & 6 & 2 & - \\
\hline \multirow[t]{2}{*}{15} & 1 & $\begin{array}{l}6 \\
3\end{array}$ & $\begin{array}{r}2 \\
22\end{array}$ & $\begin{array}{l}\text { (1) } 1 \delta+59 q \text { on } 28 \text { th day } \\
\text { (2) } 1 \sigma^{*} \\
\text { (3) } 5 \delta+10 \% \text { on } 23 \mathrm{rd} \text { day }\end{array}$ \\
\hline & & 6 & 36 & - \\
\hline \multirow[t]{3}{*}{6} & 1 & 5 & 5 & - \\
\hline & & 4 & 31 & $\begin{array}{l}\text { (1) } 2 \vec{\sigma}+93 q+2 \text { nymphs on } 31 \text { st day } \\
\text { (2) } 10+64++3 \text { nymphs on } 26 \text { th day } \\
\text { (1) } 1 z+2 q\end{array}$ \\
\hline & & 6 & 37 & 一 \\
\hline \multirow[t]{2}{*}{.7} & 1 & 12 & 5 & - \\
\hline & & 12 & 21 & - \\
\hline 8 & 1 & 12 & 2 & - \\
\hline 9 & 2 & 6 & 5 & $\begin{array}{l}\text { (1) } 44 q+31 \text { nymphs } \\
\text { (2) } 20+14 q+38 \text { nymphs }\end{array}$ \\
\hline 0 & $3 q+1 \sigma^{*}$ & 4 & 2 & $\begin{array}{l}\text { (1) } 20+24 q \\
\text { (2) } 89\end{array}$ \\
\hline 1 & $13 q+1 \sigma^{*}$ & 34 & 4 & $\begin{array}{l}(1,2) \text { A. manducator larvae with nu- } \\
\text { merous } M . \text { acasta larvae }\end{array}$ \\
\hline
\end{tabular}

Parasitology xI
Length
of life of
female female

(1) dead fly remains

(1) fly emerged

(1) dead fly remains

(1) fly emerged

50

21

$(1,2)$ dead fly remains $\quad 32$

$(1,2)$ dead fly remains $\quad 42$

(5) dead fly remains

31

33

(1-5) flies emerged

(6) A. manducator emerged

(1-6) dead fly remains

21

$(1,2)$ flies emerged

(3-6) dead fly remains

(1-2) flies emerged

(3-6) dead fly remains

(1-6) dead flies

(1-5) flies emerged

(6) A. manducator emerged 39

(1) fly emerged

(2-5) dead fly remains

$(3,4)$ dead fly remains

(2-4) flies emerged

$(5,6)$ dead fly remains

(1-6) flies emerged

(1-4) flies emerged

(5) A. manducator emerged

(6) A. manducator nymph

(7-12) dead fly remains

(1-9) flies emerged

(10-12) dead fly remains

(1-12) dead fly remains

31

(3-5) dead fy remains

(6) fly emerged

$(3,4)$ dead fly remains

30

(3-14) flies emerged

(15-29) dead fly remains

(30-34) A. manducator larvae living 
male emerged from the puparium. Consequently it was useless for the female to wait for the male to emerge as happens according to Malyshev (1913) when the parasite infests certain wasp larvae.

In eight instances the first puparia were removed, and a male together with fresh fly puparia added, the additions being made between the seventh and eighty-second days. In four cases (Nos. 4, 9, 10, 11) females, which as virgins produced males, were employed. No further parasites were produced in two of these experiments (Nos. 4, 11), but in the other two a few more of the parasites developed in 3 out of 5 and 2 out of the 6 puparia used. The five

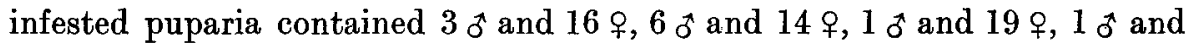
6 q and $1 \delta$ and 6 q respectively. In four cases females (Nos. 8, 12, 17, 18), which as virgins produced no males, were employed. Not a single parasite was found in the 24 puparia used.

One of the females lived 95 days, 14 lived more than 40 days. The mean length of life was 35 days.

In another experiment carried out in 1917 a remarkable number of males developed. Seven unfertilised females were given six fresh fly puparia. In two of these $6 \sigma^{*}$ were found, in one $4 \sigma^{*}$, and in one $2 \sigma^{*}$, a mean of $4.5 \sigma^{*}$ for each infected puparium.

Howard and Fiske $(1912$, p. 209) were greatly troubled with $M$. acasta in some of their experiments with tachinids, and report some interesting observations. Its chief characters are "extreme hardiness and an insidious inquisitiveness, which seems to know no bounds." These parasites attacked several different kinds of fly puparia as well as hymenopterous cocoons. "They will enter the damp earth to a depth of several inches in quest of puparia, which have been buried therein." "The eggs are deposited upon the surface of the nymph in an irregular circle surrounding the wound made by the ovipositor. They are very small and appear to swell somewhat before hatching, and if the puparium is broken open so that they are freely exposed to the air, they will fail to hatch." They noted that the male emerged first and state that "they are invariably in the great minority and their numerical strength is still further reduced by the terrific duels which follow their emergence. Notwithstanding their physical defects in the matter of sight and powers of flight, their seeming weakness otherwise and their small size, even when compared with their mates, they possess a courage and vigour which is most surprising. In the instance of a colony which had been removed, from the puparium in which it was reared through its early stages, to a small glass cell, the several males which issued well in advance of the females engaged forthwith in conflict, in the course of which a considerable number were killed. The survivors of this Lilliputian battle royal calmly awaited the issuance of the members of their harems and proceeded to mate with one and all with an ardour which seemed to know no limit."

"The females (virgin) positively refused to deposit more eggs than would have normally produced males had they been properly fertilised. Instead of 
Table III. Showing results of experiments with virgin females of $\mathrm{M}$. acasta.

$\begin{array}{cccc}\begin{array}{c}\text { No. of } \\ \text { experi- } \\ \text { ment }\end{array} & \begin{array}{c}\text { No. of } \\ \text { females } \\ \text { used }\end{array} & \begin{array}{c}\text { No. of } \\ \text { puparia } \\ \text { given }\end{array} & \begin{array}{c}\text { Age of } \\ \text { female } \\ \text { in days }\end{array} \\ 1 & 1 & 1 & 6 \\ 2 & 1 & 1 & 6 \\ 3 & 1 & 1 & 7 \\ 4 & 1 & 1 & 5 \\ 5 & 1 & 2 & 6 \\ 6 & 1 & 2 & 6 \\ 7 & 1 & 2 & 7 \\ 8 & 1 & 4 & 4 \\ 9 & 1 & 5 & 4\end{array}$

Result

dead fly remains +20

dead fly nymph

dead fly nymph +1 \%

dead fly nymph +1 \%

(1) dead fly nymph

(2) dead A. manducator

dead fly remains in both

(1) dead A. manducator +2

(2) dead $A$. manducator $+2 \sigma$

(1) fly emerged

$(2,3,4)$ dead fly remains

$(1,2)$ flies emerged

(3) dead fly remains

(4) dead fly remains $+2 \delta$
(1) fly emerged

$(2,3,4)$ dead fly remains

(5) dead fly remains $+1 M$. acasta larva

(1) fly emerged

$(2,3,4,5)$ dead fly remains

(6) dead fly remains +10

$(1,2,3)$ flies emerged

$(4,5,6)$ dead fly remains

$(1,2)$ flies emerged

$(3,4,5,6)$ dead fly remains

$(1,2)$ flies emerged

$(3,4)$ dead fly remains

$(5,6)$ braconid larvae

$(1,2)$ dead fly remains

(3) dead fly remains $+1 \%$

(4) dead braconid larva $+1 \delta$

(5) $A$. manducator emerged

(6) A. manducator dead

(1) A. manducator dead

$(2,3,4,5,6)$ dead fly remains

(1) Ichneumon emerged

$(2,3,4)$ flies emerged

$(5,6)$ dead fly remains

(1-6) dead fly remains

(1) A. manducator emerged

(2) dead fly remains +10

$(3,4,5,6)$ dead fly remains

(1-2) flies emerged

$(3,4,5,6)$ dead fly remains

(1-6) dead fly remains

(1) fly emerged

(2-6) dead fly remains

(1-6) dead fly remains

(1-4) flies emerged

(5-6) dead fly remains

(1-4) flies emerged

(5-6) dead fly remains

(1-6) dead fly remains

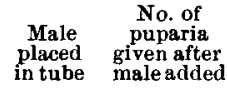

Result$$
\text { - } \quad-\quad 6 \quad-60
$$$$
\begin{array}{llll}
- & - & - & 7
\end{array}
$$

- -5

82nd day 5 dead fly remains in all $\quad 95$

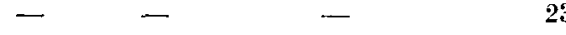

$\begin{array}{llll}- & - & - & 42\end{array}$

- - -

14th day 5 dead fly remains in all 21

14th day $5 \quad$ (1) $10+19$ क 12

(2) $10+60$

(3) $10+6$

$(4,5)$ dead fly remains

13th day $6 \quad$ (1) $3 \delta^{\star}+16$ ㅇ 26

(2) $6 \sigma^{x}+149$

$(3,4,5)$ flies emerged

(6) dead fly remains

14th day $8(1,2,3,4)$ flies emerged $(5,6,7,8)$ dead fly remains

14th day $6 \quad(1,2,3)$ flies emerged 21 $(4,5,6)$ dead fly remains

7th day $6 \quad(1-6)$ flies emerged

11th day 6 (1) fly emerged

27

(2) $A$. manducator emerged $(3,4,5,6)$ dead fly remains

$?$

40

49

55

49

53

49 
Table III (continued).

$\begin{array}{cccc}\begin{array}{c}\text { No. of } \\ \text { experi- } \\ \text { ment }\end{array} & \begin{array}{c}\text { No. of } \\ \text { females } \\ \text { used }\end{array} & \begin{array}{c}\text { No. of } \\ \text { puparia } \\ \text { given }\end{array} & \begin{array}{c}\text { Age of } \\ \text { female } \\ \text { in days }\end{array} \\ 27 & 1 & 6 & 6 \\ 28 & 1 & 6 & 6\end{array}$

(1) fly emerged

(2) A. manducator emerged (3-6) dead fly remains

$\begin{array}{llll}28 & 1 & 6 & 6 \\ 29 & 1 & 6 & 6 \\ 30 & 1 & 6 & 6 \\ 31 & 1 & 6 & 6 \\ 32 & 1 & 6 & 6 \\ 33 & 1 & 6 & 6\end{array}$

(1-3) flies emerged

(4) A. manducator nymph

(5) dead fly remains

(6) dead fly remains $+1 \%$

(1) A. manducator emerged (2-6) dead fly remains

(1-2) flies emerged

(3) A. manducator emerged (4-6) dead fly remains

(1) fly emerged

(2-5) dead fly remains

(6) dead A. manducator

(1-3) flies emerged

(4-6) dead fly remains

(1-2) flies emerged

(3-4) dead fly remains

(5) dead fly remains +1 o

(6) dead fly remains +4 o

$\begin{array}{lll}34 & 1 & 6 \\ 35 & 1 & 6 \\ 36 & 1 & 6 \\ 37 & 1 & 6 \\ 38 & 1 & 6\end{array}$

(1-3) flies emerged

(4-5) dead fly remains

(6) dead fly remains $+4 \delta$

(1-2) flies emerged

(3-6) dead fly remains

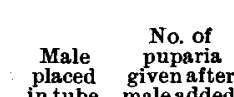

placed given after

Result

Length
of life

of

in day:

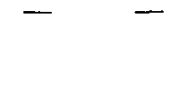

19

37

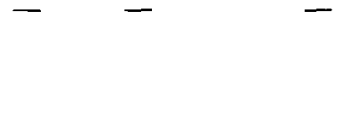

(1-6) dead fly remains

(1-5) dead fly remains

(6) A. manducator larva

(1-2) flies emerged

(3-4) dead fly remains

(5) dead fly remains $+2 \delta$

(6) dead A. manducator

$\begin{array}{lllll}39 & 1 & 9 & ? & (1-5) \text { flies emerged }\end{array}$

(6) dead fly remains

(7) A. manducator dead

(8-9) A. manducator larvae

$\begin{array}{lllll}40 & 1 & 12 & 6 & (1-3) \text { flies emerged }\end{array}$

(4-8) dead fly remains

(9-11) A. manducator dead

(12) A. manducator emerged

$41 \quad 1 \quad 12$

(1-10) dead fly remains

(11-12) dead A. manducator

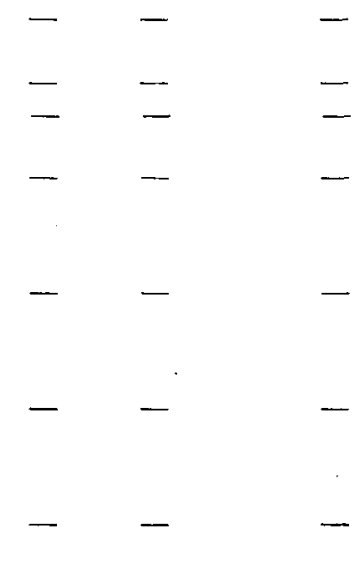

depositing sufficient to provide for the complete consumption of the host, only four or five would be deposited at a time, and notwithstanding that after the depositing of what probably amounted to barely 5 per cent. of those which filled their abdomens fairly to bursting, they ceased, and nothing short of impregnation seemed to arouse their maternal instincts again." "This progeny, as was expected, was exclusively of the male sex, which when afforded opportunity, promptly united with their virgin mothers, who thereupon displayed the normal desire to deposit their eggs." From such eggs both sexes were reared. 
Malyshev (1913) made some very interesting observations on the habits of $M$. acasta as a parasite of solitary wasps. He states that the females can only fly $1-2 \mathrm{~mm}$. The females frequently wound the wasp larvae with their ovipositors and suck the wounds. Such larvae never moult, make a cocoon or transform, but are immobilised and finally die, though very slowly. The females lay 200-300 eggs, or perhaps more. The males emerge first and fights ensue in which some are decapitated or loose their legs or abdomens. He notes that virgin females only lay four or five eggs, which give rise to males. Such females then wait in the neighbourhood and eventually mate with the males which emerge, and within 24 hours lay numerous eggs. The males never leave the nests in which they were hatched. He states that $M$. acasta attacks the

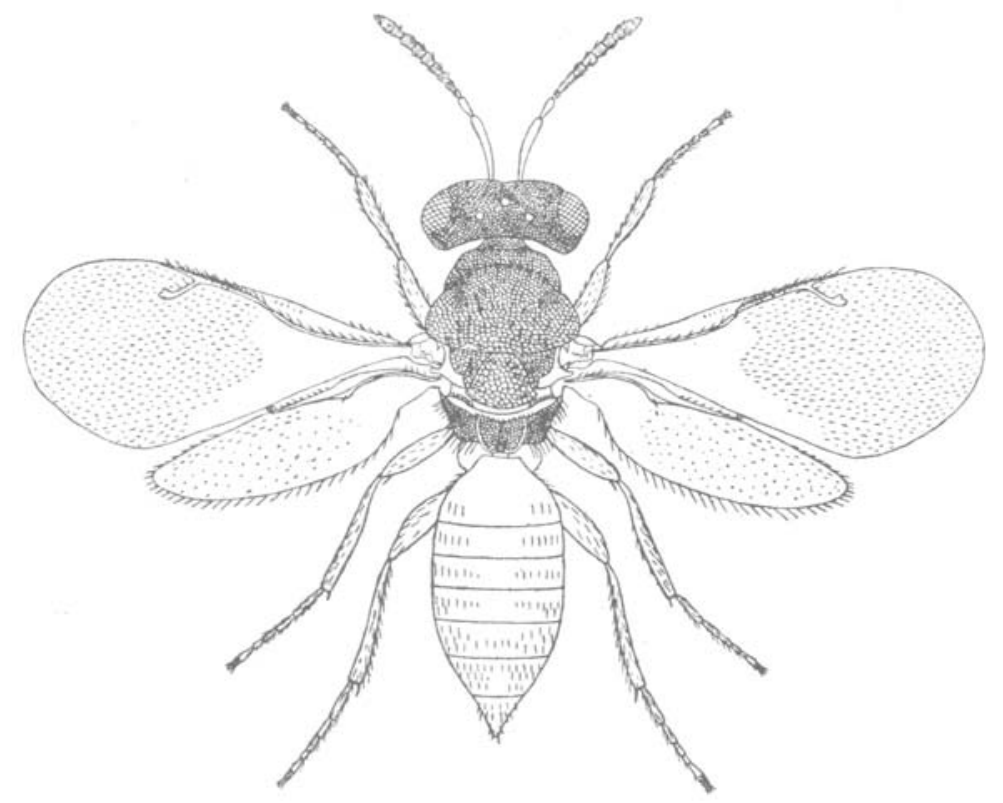

Fig. 13. Dibrachys cavus 우. $\times 20$.

tachinids which parasitise the wasps. They never lay their eggs on the tachinid ( $P$. signatus) larvae, which are very lively, but wait till they pupate and oviposit on the puparia.

\section{Dibrachys cavus.}

D. cavus was first encountered in small numbers in puparia collected in the autumn of 1914. From thirteen of these 37 of the parasites emerged in April and May 1916. Fly puparia collected in the autumn of 1915 showed however heavy infection with this parasite. Some of these parasites emerged in September 1916, namely $19 \delta$ and 65 from 15 puparia. The remainder did not commence to emerge till March or April 1917. Then 433 D. cavus emerged from 154 puparia, the sexes being nearly equal in numbers. The numbers 
ranged from 2 to 9 from each puparium. Some of the jars in which the fly puparia were kept were covered with cloth in January 1916 and in these no chalcids were found. Consequently the infection occurred in the spring of 1916. All these chalcids occurred in puparia parasitised by $A$. manducator, but it is probable that at the time infection took place no normal puparia were present, the flies having already emerged. Experimentally $D$. cavus oviposits in the normal puparia of many common flies, including $M$. stabulans and $P$. greenlandica. The process is very similar to that which occurs in the case of $M$. acasta. D. cavus in emerging makes a round opening much larger than that made by $M$. acasta, which may be situated in any part of the puparium.

Several experiments were carried out in which females together with males of $D$. cavus were confined in tubes with fly puparia. In one 15 puparia were used. In four of these puparia $5 \delta$ and 45 omerged; one contained dead adults and 10 dry fly remains. A single fertilised female was confined with a different puparium on consecutive days. From six of these $6 \delta$ and 50 q emerged. This parasite therefore seems to be less prolific than $M$. acasta.

In another experiment 16 of the chalcids, males and females, were confined in one tube with eight fresh fly puparia. The parents were all dead by the seventeenth day, and the new generation began to emerge on the thirty-sixth day. Altogether $20 \delta$ and 63 o emerged, giving a mean of $2 \delta$ and $8 \%$ for each puparium. One puparium contained $2 \delta$ and $12 \%$, another $5 \sigma^{\star}$ and 9 a and another 4 of and 11 i. All the puparia were parasitised.

\section{Nasonia brevicornis.}

This chalcid was first obtained from puparia collected in the summer of 1916, and emerged at the end of April 1917. From 16 puparia, unparasitised by A. manducator, 14 of and 167 i emerged, a mean of 11 chalcids to each infected puparium. Puparia collected in the autumn of 1916 and kept outside yielded in May 191738 o and 369 ㅇ. Some of these autumn puparia had been parasitised by $A$. manducator. The proportion of males to females was therefore about 1 to 10 in each instance. Some of these autumn puparia remained intact, and were dissected in March 1918. Of these 28 were found to contain living chalcid larvae and were kept in tubes in a warm room. Nineteen of these 28 showed infection with $A$. manducator. Adult $N$. brevicornis, 11 ond 48 , emerged in May 1918, a year and a half after the puparia were collected.

Both the males and females show great variations in size, some of the former being very small and many of the latter very large. The males have very short wings and are unable to fly. Unlike the males of $M$. acasta they emerge from the fly puparia, and run rapidly amongst the earth and debris and are difficult to find and catch. As in the case of $D$. cavus the hole through which the chalcids emerge may be situated in any part of the puparium.

Ten females confined in a tube on April 30, 1917, with 19 puparia were all dead in 13 days. From 16 of these puparia $24{ }^{\star}$ and 156 emerged between the twenty-fourth and twenty-ninth days from the commencement of the 
experiment. The remaining three puparia contained dead fly remains. The greatest number of the parasites from one puparium was $2 \sigma^{t}$ and 11 o.

In a second experiment six of the chalcids were confined in a tube with 12 puparia on May 1, 1917. All were dead within 15 days. 29 o and 102 \%

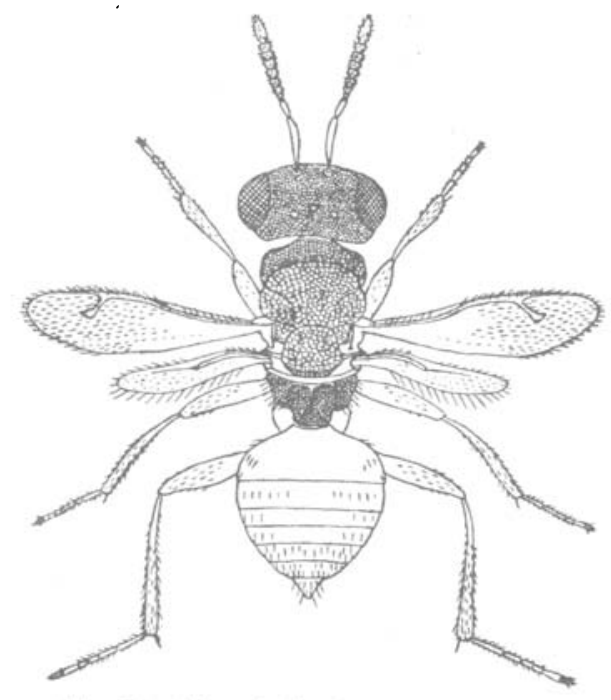

Fig. 14. Nasonia brevicornis $\hat{\sigma} \cdot \times 20$.

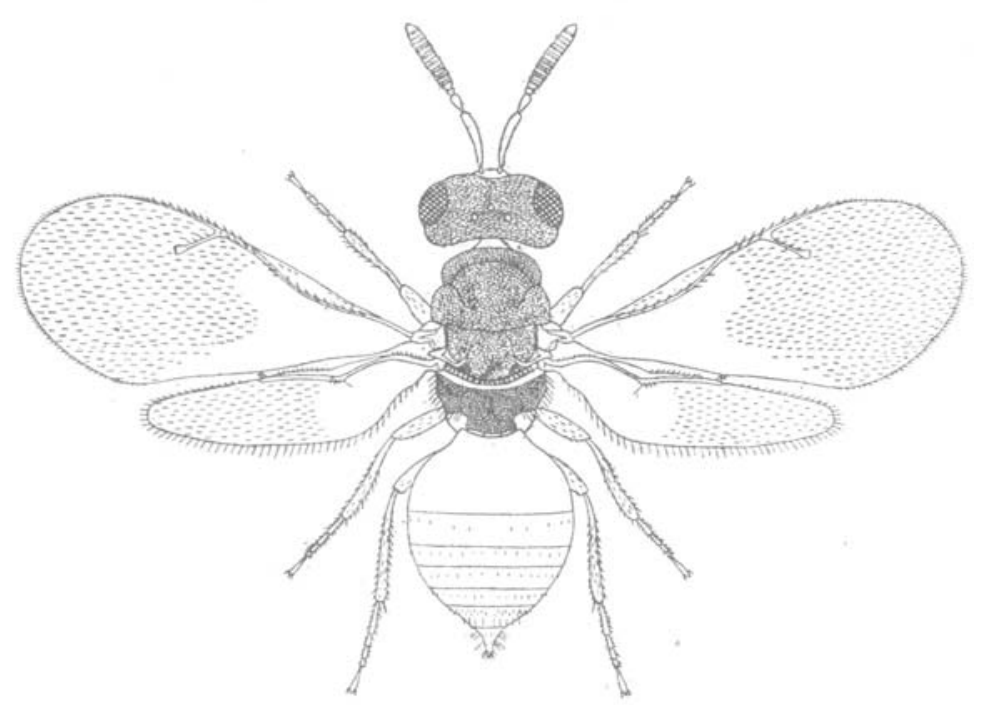

Fig. 15. Nasonia brevicornis 오. $\times 20$.

emerged within 47 days of the commencement of the experiment. On dissecting these puparia 10 chalcid nymphs were found also.

In a third experiment six females were confined with 12 puparia on May 1. Within 30 days $14 o^{\star}$ and $70 \%$ emerged from six of the puparia. From 
one of these puparia $3 \delta$ and 12 emerged. The others were subsequently dissected and found to contain dead fly remains.

In a fourth experiment two females were confined with six puparia on May 3, 1917. $4 \delta$ and 39 omerged on May 28 from three of the puparia. On dissecting the remaining puparia one dead male, two dead females and 10 dead nymphs were found in one, several dead chalcid larvae in another, and dead fly remains in the third.

In a fifth experiment a single female was confined with three puparia on May 1. From these puparia 7 and 27 o emerged on the twenty-sixth day.

In these experiments 40 infected puparia yielded $78 \delta$ and 394 o a mean of 2 and 10 from each puparium; the number emerging from each puparium

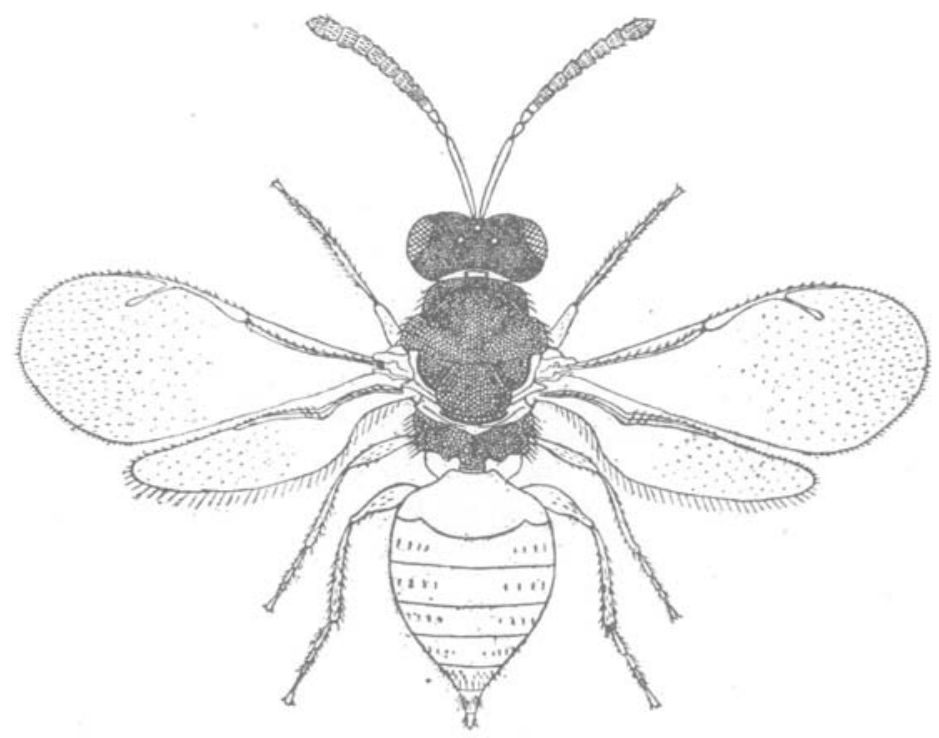

Fig. 16. Muscidifurax raptor 우. $\times 20$.

being almost the same as from the naturally infected puparia. In this chalcid the proportion of males to females is much greater than in $M$. acasta, and the number of eggs deposited in each puparium much less.

\section{Muscidifurax raptor.}

A few specimens of the chalcid, $3 \%$ and 12 \%, emerged between August 23 and September 26, 1917, from puparia collected during July of that year.

Five $q$ to which $20 \mathrm{fly}$ puparia were given lived 40 to 50 days. From two of the puparia single females emerged, the other 18 containing dry fly remains.

\section{Necremnus leucarthros Thoms.}

Six examples of this chalcid, $1 \delta$ and 5 , emerged between August 5 and September 3, 1917, from puparia collected earlier in the summer. 


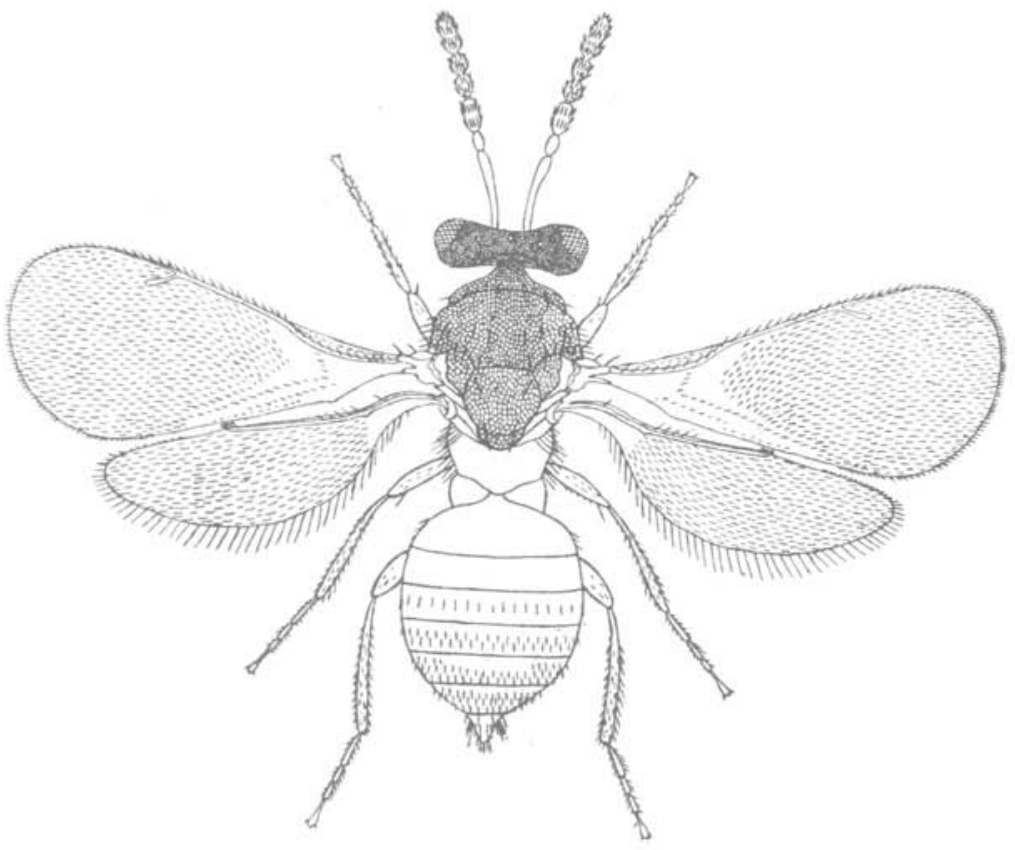

Fig. 17. Necremnus leucarthros ‥ $\times 20$.

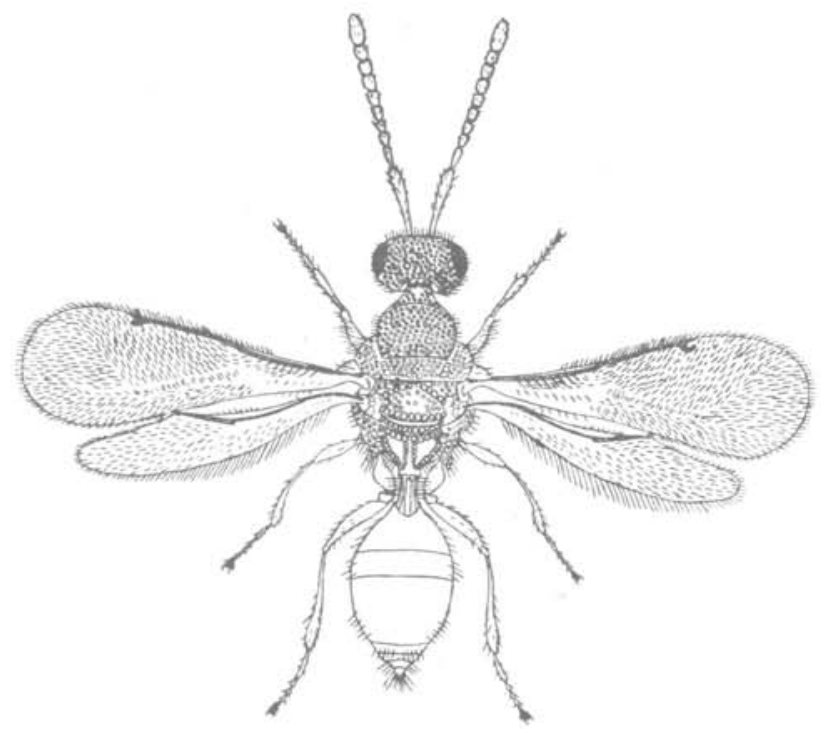

Fig. 18. Spalangia hirta. $\times 20$.

Spalangia hirta Hal.

A specimen emerged on August 5, 1917, from puparia collected on July 5, 1917. 


\section{Stenomalus muscarum.}

This chalcid was not obtained from fly puparia, but in view of the fact that it has been found hibernating in company with flies on several occasions some observations on its seasonal prevalence may be of interest. In 1916 large numbers were present on the windows on March 3 and 18. Few were noticed during the summer, but hundreds were observed on the windows on September 27 and 28, October 1 and 2, and November 15. In 1917 a feww were noticed on the windows on April 7, 20 and 29 and very large numbers on September 6, 24 and 29. In 1918 they were numerous on the windows on March 25. Attempts were made to induce females to oviposit in fly puparia, but without success.

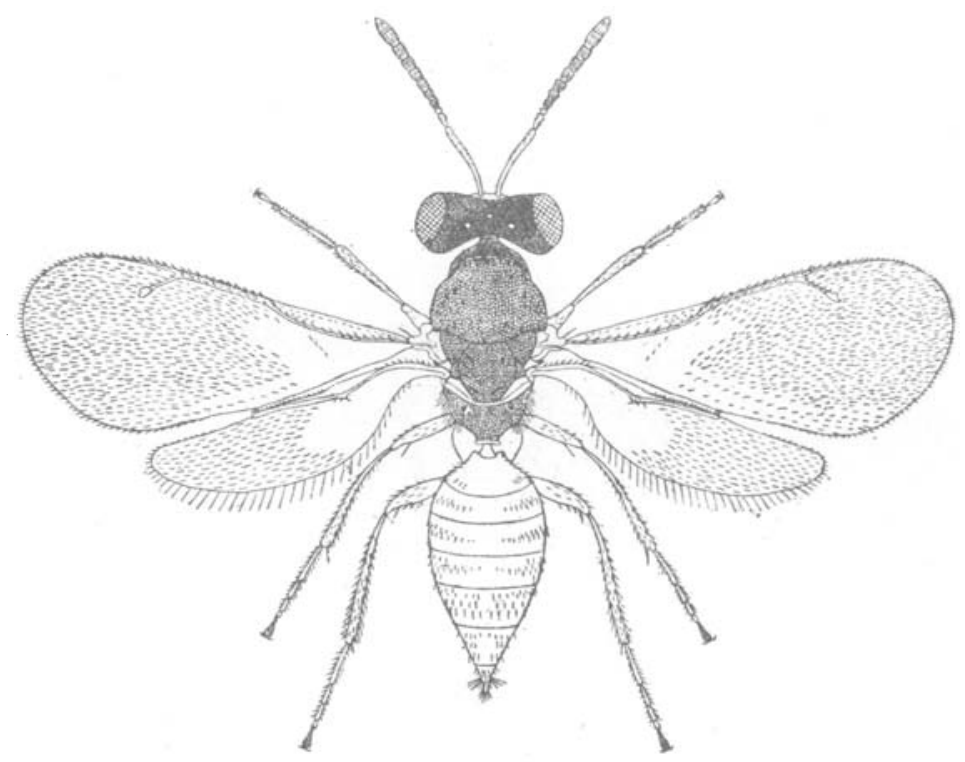

Fig. 19. Stenomalus muscarum ㅇ. $\times 20$.

\section{BRACONIDAE.}

Alysia manducator.

A. manducator has been obtained in considerable numbers each year from several series of fly puparia bred under natural conditions.

The observations made in 1915 and previously recorded $(1916$, p. 524) showed that numerous specimens of $\boldsymbol{A}$. manducator emerged from puparia collected from shady situations in the autumn of 1914. A small batch consisting of 209 specimens appeared in the spring of 1915 , and after an interval of three months a second and larger batch of 1115 specimens, being 83 per cent. of the total number. Of all the puparia collected 61 per cent. were infected by this parasite. Further it was shown that the time of emergence in the spring 
is greatly influenced by the temperature at which the parasitised fly puparia are kept $(1916$, p. 531).

Fly puparia collected from small carcases lying $(A)$ in sunny, and $(B)$ shady situations during the autumn of 1915 were placed in boxes covered with fine gauze, which were left during the following winter at the breeding places. From these puparia very numerous examples of $A$. manducator emerged during 1916.

\begin{tabular}{|c|c|c|c|c|c|}
\hline \multirow[b]{2}{*}{ Situation } & \multirow[b]{2}{*}{$\begin{array}{l}\text { No. of fiy } \\
\text { puparia }\end{array}$} & \multicolumn{2}{|c|}{ A. manducator } & \multicolumn{2}{|c|}{$\begin{array}{l}\text { Subsequent examination of } \\
\text { puparia remaining intact. } \\
\text { A. manducator }\end{array}$} \\
\hline & & $\begin{array}{l}\text { Spring batch } \\
9 \text { April-30 May }\end{array}$ & $\begin{array}{l}\text { Autumn batch } \\
13 \text { Sept.-15 Nov. }\end{array}$ & Dead adults & Living larvae \\
\hline$A$, sunny & 4742 & $673{ }^{x}+159$ 우 & $148 \sigma^{x}+43$ 우 & 179 & 9 \\
\hline$B$, shady & 5163 & $158 \sigma^{x}+140 \phi$ & $1912 \sigma+447$ 우 & 290 & 41 \\
\hline
\end{tabular}

At least 25 per cent. of the puparia from the sunny situation and 57 per cent. of those from the shady situation were infected with $A$. manducator, but while from the sunny situation 81 per cent. of the parasites emerged in the spring, from the shady situation 83 per cent. of them emerged in the autumn. In each situation more than three-quarters of all the specimens were males, and it was noticed that a large proportion of the males emerged before the females commenced to appear both in the spring and autumn batches. In the sunny situation between April 9 and May 9471 ond only 26 omerged, and in the shady situation between September 27 and October $161416 \delta^{\circ}$ and only 140 o. Possibly the predominance of males is due to the fact that virgin females very readily deposit eggs which produce males (see p. 380).

From the puparia mentioned there also emerged:

\begin{tabular}{|c|c|c|c|c|c|c|c|}
\hline \multirow[b]{2}{*}{ Situation } & \multirow[b]{2}{*}{ Living flies } & \multirow[b]{2}{*}{ Dead flies* } & \multicolumn{2}{|c|}{$\begin{array}{l}\text { Puparia containing } \\
\text { A. cephalotes }\end{array}$} & \multirow[b]{2}{*}{ Figitids } & \multicolumn{2}{|c|}{ D. cavus } \\
\hline & & & Living & Dead* & & Adults & Larvae* \\
\hline$A$, sunny & $1040 \delta+1107 q$ & 989 & 192 & 122 & 5 & 13 & 62 \\
\hline$B$, shady & 843 ơ 677 q & 501 & 26 & 6 & 25 & 2 & 93 \\
\hline
\end{tabular}

In this instance secondary chalcid infection exerted little influence on the results. Occasionally, however, secondary chalcid infection has a great influence on the numbers of $\boldsymbol{A}$. manducator emerging in the autumn. Such an instance has been illustrated in detail previously (1916, pp. 533-535), puparia infected with $A$. manducator in the "sun tin" being attacked by $M$. acasta, while those in the "shade tin" escaped. In the former during the autumn numerous chalcids emerged but not a single $A$. manducator, while in the latter more than a thousand $A$. manducator appeared, but no chalcids.

It may be of interest to inquire how far the appearance of the spring and autumn batches is influenced by temperature. Some puparia collected in the autumn of 1915 were kept in rooms at different temperatures. In the three cooler rooms both spring and autumn batches appeared, but in the three warmer rooms spring batches only. Since the latter rooms were very warm 
and dry the larvae due to produce imagines in the autumn may have been killed, and the single experiment is not conclusive.

Fly puparia collected in the autumn of 1916 from a sunny situation were kept under observation throughout 1917 with the following results:

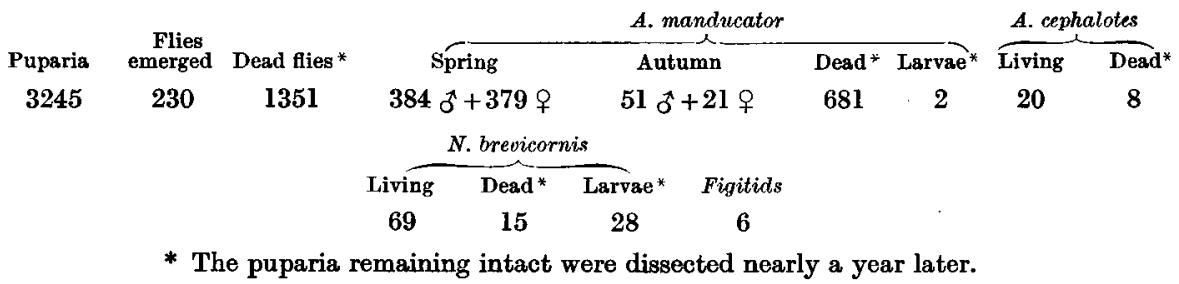

In 1917 the spring was very cold until the end of April, but after that date the weather was very hot, and possibly it was due to this that so many of the fly nymphs and braconid larvae died.

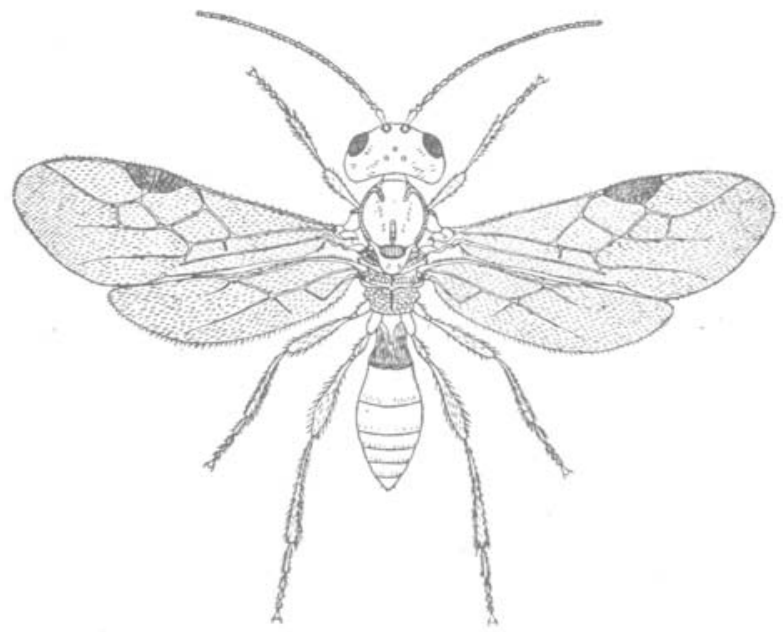

Fig. 20. Alysia manducator ㅇ. $\times 5$.

In this instance as in 1916 the great majority (90 per cent.) of the specimens of $A$. manducator which emerged did so in the spring. Of the fly puparia at least 1565 (48 per cent.) were infected with $A$. manducator, namely 1518 in which the braconid was found and 47 secondarily infected by $N$. brevicornis.

At various times during the summer months of 19164280 puparia were collected from animal remains, and from these both the flies and their parasites emerged during the same season.

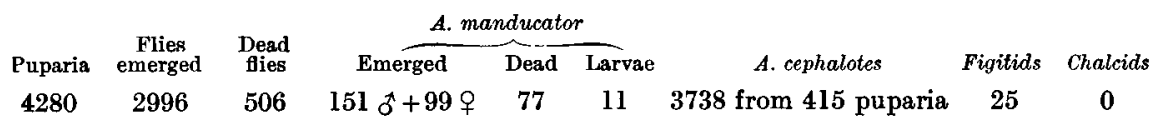

Only 8 per cent. of these puparia were infected with $A$. manducator. 
In 19172188 fly puparia were collected on July 5 from similar situations.

\begin{tabular}{|c|c|c|c|c|c|c|}
\hline \multirow[b]{2}{*}{ Puparia } & \multirow{2}{*}{$\begin{array}{c}\text { Flies } \\
\text { emerged }\end{array}$} & \multirow{2}{*}{$\begin{array}{l}\text { Dead } \\
\text { flies }\end{array}$} & \multicolumn{2}{|c|}{ A. manducator } & \multicolumn{2}{|c|}{ N. brevicornis } \\
\hline & & & Emerged & Dead & Adults from & Larvae in \\
\hline 2188 & 1791 & 277 & $13 \alpha+17$ 우 & 23 & 59 & 8 \\
\hline
\end{tabular}

Only 2 per cent. of these puparia were infected with $A$. manducator.

Of the 16,028 puparia collected in the autumns of 1914-15-16 from sunny and shady situations 7041 or 43 per cent. were infected with $A$. manducator, while of the 4787 puparia collected during the summer months of 1916-17 only 508 or 10 per cent. were infected.

These observations seem to indicate that infection with $A$. manducator is much greater in the autumn than during the summer. The parasite, however, is abundant throughout the season for it was observed attacking fly larvae from May 30 to November 1, 1916.

Observations on the habits of A. manducator.

Females were often kept under observation when depositing their eggs under natural conditions. The larger larvae seem to be selected for attack. The parasite seizes the larva with its legs, and in spite of the violent struggles of the victim, during which the pair turn over and over, seldom releases its hold. The struggle usually lasts several seconds. Finally the ovipositor is inserted and very soon afterwards the larva ceases to struggle, and remains motionless. The ovipositor remains inserted for 40-50 seconds, and is then withdrawn. After a period of one or two minutes the larva begins to move again and eventually regains full activity. As soon as the parasite leaves one larva it attempts to attack another. After a time it becomes battered and feeble and is only able to move slowly, owing to its struggles with a succession of larvae.

The parasites usually seem to be able to secure a better hold on larvae moving towards them than on larvae moving away from them, for the former very seldom escape, while the latter occasionally do so.

The ovipositor may be inserted into the anterior or posterior end of the larvae or more rarely into the middle.

Sometimes the parasites walk over masses of large larvae, select several and oviposit in them. Occasionally they oviposit in larvae feeding under a thin shell of meat, driving their ovipositors through the shell and ovipositing without seizing the larvae.

While males kept in confinement sometimes remain alive for 15 days, females confined with larvae, even though provided with places on which they can rest, invariably die in three or four days.

Experiments with A. manducator.

A large fertilised female $A$. manducator was put into a jar with 544 large fly larvae, chiefly $C$. erythrocephala. The parasite was found dead on the 
fourth day. On dissecting the body 343 eggs were found in the ovaries. Of the larvae 80 died, possibly due to infection by the insertion of the ovipositor (see Fabre, p. 408). From 170 puparia flies emerged within 25 days and from 193 there emerged $47 \AA$ and $146 \% A$. manducator between the thirtieth and ninetyfifth days. The remaining 101 puparia were examined on the hundred and seventieth day; 88 contained dead fly remains, 5 dead adult $A$. manducator and 8 dead $A$. manducator larvae. In this case the female $A$. manducator deposited eggs in at least 206 of the larvae provided.

Under more natural conditions it is likely that she would have infected a greater number as the ovaries contained at least 549 eggs.

In another experiment a fertilised female $A$. manducator was given 58 large larvae in succession, and was seen to insert its ovipositor into each in turn. All these larvae pupated. From five flies emerged on the twenty-fifth day, and from 28 of them 10 ot and 18 o $A$. manducator between the thirty-fifth and ninety-fifth days. The remaining 25 puparia were examined on the hundred and seventieth day. Seven contained dead fly remains and 18 dead adults or larvae of $A$. manducator.

In this case all the parasitic eggs were deposited on the same day in larvae of the same age, which were kept under identical conditions, yet the first adult A. manducator emerged on the twenty-fifth day and the last on the ninety-fifth day. All the $10{ }^{*}$ and 4 of the $q$ emerged between the twenty-fifth and thirtyseventh days, and the other 10 q between the sixty-first and ninety-fifth days.

In a third experiment a fertilised female $A$. manducator was placed in a glass jar and four large fly larvae introduced. The parasite soon oviposited in each larva and after an interval when the larvae began to move about attacked each a second time. The experiment was repeated until she had apparently oviposited twice in 19 larvae. Five of these larvae died, and the other 14 pupated. From one a fly emerged on the twenty-fifth day. $2 \delta$ and 1 ㅇ $A$. manducator emerged on the thirty-first, forty-second and forty-third days and 4 o between the seventy-first and eighty-fourth days. The six remaining puparia were examined on the hundred and seventieth day. Three contained dead fly pupae, one a dead $A$. manducator and two dead $A$. manducator larvae.

This experiment shows that flies may sometimes develop from larvae in which the parasite has presumably deposited two eggs and that from such larvae only single specimens of $A$. manducator emerge.

In a fourth experiment an unfertilised female $A$. manducator was placed in a jar with 191 large fly larvae. She was found dead on the fourth day, and on dissection only 17 eggs were found in the ovary.

Of the larvae 76 died and the rest pupated. From these 19 flies emerged on or before the twenty-first day. Between the forty-first and forty-seventh day $42 \sigma^{*}$ and between the seventy-second and seventy-ninth $29 \sigma^{*}$ of $A$. manducator emerged. The remaining 25 puparia were examined on the hundred and seventieth day. Dead fly remains were found in 13 and dead $A$. manducator in 12 . 
This experiment shows that unfertilised females oviposit readily, and that large numbers of males only are produced. As noticed in all other cases there were two distinct periods of emergence.

From larvae first attacked by $A$. cephalotes and subsequently by $A$. manducator only $A$. cephalotes emerged.

A. manducator were never seen to attack larvae feeding on faecal material.

\section{Aphaereta cephalotes Hal.}

Numerous specimens of $A$. cephalotes have been reared from naturally infected puparia kept throughout the winter in glass jars. About 10 adults in the proportion of $2 \sigma^{7}$ to 8 emerge from the larger puparia. This parasite usually begins to emerge from over wintered puparia at the end of April and continues to emerge throughout May. There is no autumn batch such as occurs in the case of $A$. manducator.

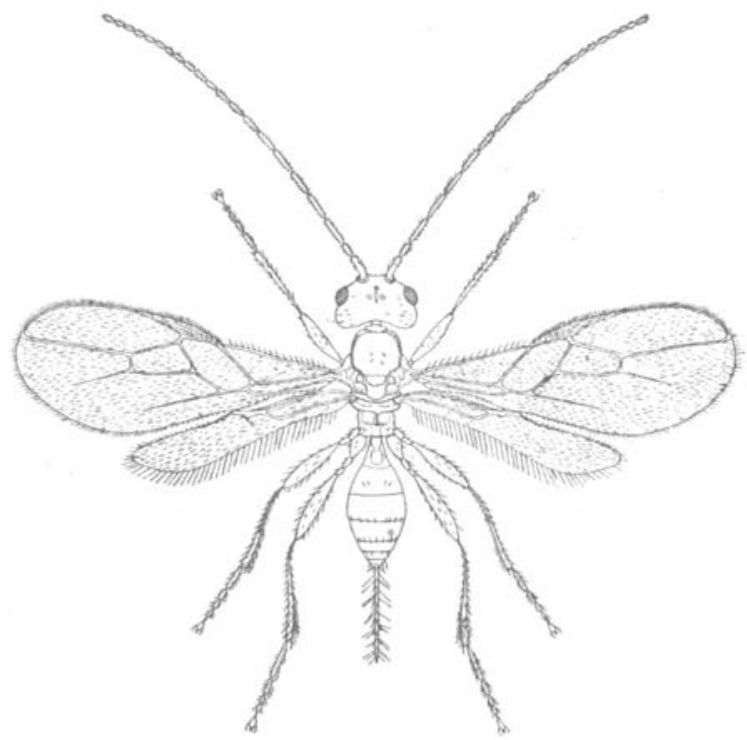

Fig. 21. Aphaereta cephalotes ․ $\times 10$.

Out of 4742 puparia from a sunny situation kept under observation in the winter 1915-16, 314 ( 6 per cent.) were infected with $A$. cephalotes and produced 2496 individuals, whereas of the 5163 puparia from a shady situation only $32(0 \cdot 6$ per cent.) were infected with $A$. cephalotes.

$A$. cephalotes seems to be afraid of the larger larvae and can hardly be - induced to attack them even when no other larvae are present, but it oviposits very readily in small fly larvae. The procedure of the parasite when ovipositing resembles that of $A$. manducator, but the ovipositor is inserted for a much longer period, in one case as long as 7 minutes, and the larvae remain motionless longer, up to 30 minutes. 
Both exposed larvae and those hidden under folds of skin, etc., are attacked. The parasite frequents such situations and often inserts its abdomen into clefts and seems to feel for hidden larvae with its ovipositor.

At least from some puparia the males emerge first. For example from one puparium $2 \pi$ emerged and on examining the contents of the puparium $2 \%$ nearly fully developed were found and several female nymphs.

Occasionally only one or two of these parasites develop in a puparium, and these are often very large.

This parasite frequents both animal remains and faecal material throughout the summer and autumn.

\section{Aspilota fucicornis Hal.}

Several specimens of this small braconid were reared in August, 1917, from puparia found in excrement in July.

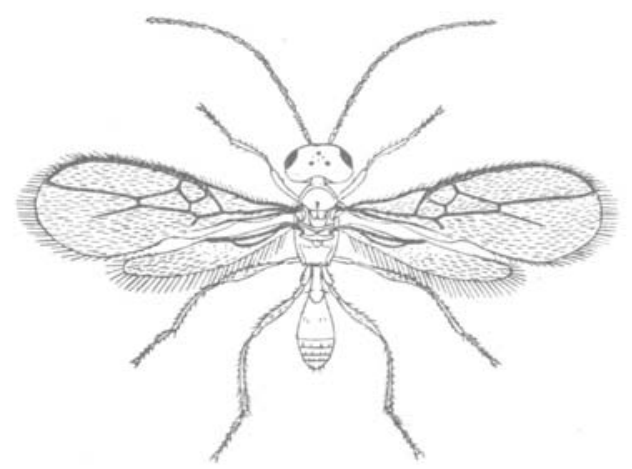

Fig. 22. Aspilota fucicornis. $\times 15$.

Aspilota nervosa Hal.

A single specimen emerged in the spring of 1917 from puparia collected in the previous autumn.

\section{CONCLUSIONS.}

1. In the year 1915 flies caught in a trap baited with excrement were most abundant in August and September, in 1916 in July and in 1917 in May and June. In each year the curve indicating the number of flies caught corresponds with the curve for the maximum temperatures recorded by a thermometer exposed in the sun.

2. Flies spend a very large proportion of their time in cleaning themselves, and the procedures usually follow each other in a definite order.

3. Empusa disease occurs in several species of flies. Specimens of $C$. erythrocephala, L. caesar, H. dentipes, $F$. canicularis, A. radicum, S. carnaria, $M$. corvina and $S$. stercoraria suffering from the disease have been noticed.

4. Certain Gamasid mites destroy both fly eggs and young larvae.

5. Certain species of beetles destroy large numbers of fly puparia. 
6. Numerous parasites were obtained from naturally infected fly puparia. Most of these over-wintered in the puparia. The parasites include numbers of the five most important families of the Hymenoptera parasitica or Terebrantia, namely the Cynipidae, Proctotrypidae, Ichneumonidae, Chalcididae and Braconidae. Infection with species belonging to the last two families is very common.

7. In 1915 great numbers of the chalcid $M$. acasta emerged from naturally infected fly puparia. Experiments and observations on these parasites showed that they frequently parasitised puparia already infected with the braconid, $A$. manducator. The males, which are blind, unable to fly and relatively few in numbers, reach maturity before the females in the same puparia, and the stronger specimens destroy the weaker. The males never leave the puparia in

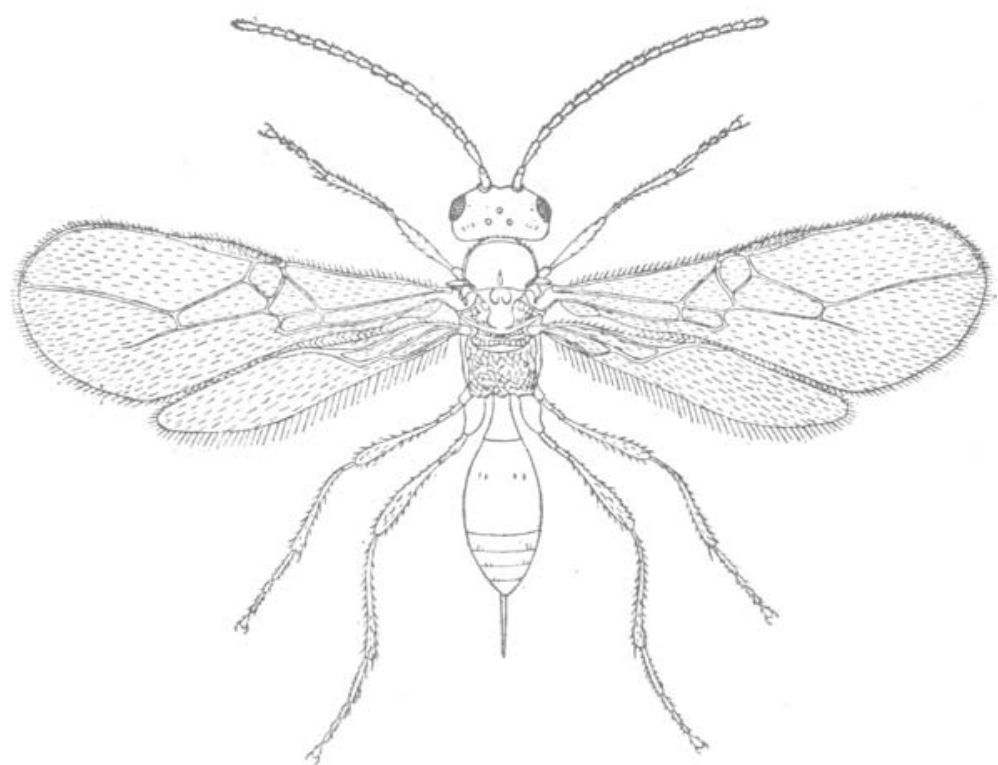

Fig. 23. Aspilota nervosa. $\times 10$.

which they emerge, but mate with the females before the latter escape from the puparia. Fertilised females lay large numbers of eggs from which a few males and numerous females develop, but virgin females only lay a few eggs from which males develop. If fertilised subsequently numerous eggs are deposited from which both males and females develop. These parasites oviposit in puparia, but never in larvae.

8. In 1916 and $1917 N$. brevicornis and D. cavus were the chalcids most commonly found parasitising fly puparia.

9. The braconid, $A$. manducator, was bred very commonly each year from fly puparia collected in the autumn. In 191561 per cent. of the puparia were infected. In each year some of these parasites from the same batch of puparia 
emerged in the spring and some in the autumn. The cause of this has not been ascertained, but it has been shown that the imagines from eggs laid by a single female appear at different times, even though the parasitised fly larvae are kept under identical conditions. These parasites attack large larvae. Virgin females readily attack larvae and lay numerous eggs from which males emerge. Only one parasite emerges from each infected puparium.

10. A. cephalotes, a smaller braconid, was bred frequently. It attacks small fly larvae. Several of the parasites emerge from each infected puparium.

\section{REFERENCES.}

FABRe, J. H. (1913). The Life of the Fly. Translated by de Mattos, A. T.

Graham-Smrth, G. S. (1916). Observations on the habits and parasites of common flies. Parasitology, virr. 440.

Howard, L. O. and Fiske, W. F. (1912). The importation into the United States of the parasites of the Gipsy Moth and the Brown-tail Moth. U.S. Dept. of Agricult. Bureau of Entomology. Bull. No. 91.

Malyshev, S. I. (1913). Zur Biologie der Odynerus-Arten und ihrer Parasite. Horae Societatis Entomologicae Rossicae, XL. 1-58. 